\title{
A Numerical Study of the Effects of Using Reformer Gas on Ignition Characteristics under Dual-Fuel Engine-Relevant Conditions
}

\author{
Guo Junwu (iD) and Guo Leyang \\ Shanghai Maritime University, Marine Merchant College, No. 1550 Haigang Avenue, Shanghai, China \\ Correspondence should be addressed to Guo Junwu; jwguo@shmtu.edu.cn
}

Received 14 November 2021; Revised 26 December 2021; Accepted 15 January 2022; Published 21 February 2022

Academic Editor: YANQING NIU

Copyright (c) 2022 Guo Junwu and Guo Leyang. This is an open access article distributed under the Creative Commons Attribution License, which permits unrestricted use, distribution, and reproduction in any medium, provided the original work is properly cited.

\begin{abstract}
Natural gas/diesel dual-fuel engine has become an urgent need to alleviate the energy crisis and reduce emissions. As an additive, reforming gas can improve the combustion process of dual-fuel engines because it improves the combustion rate and compensates for the low reactivity of natural gas. Therefore, it is of great significance to study the ignition characteristics of natural gas diesel blends by adding $\mathrm{H}_{2}$ and syngas. Based on ANSYS Chemkin 17.0 software, the ignition delay time was solved by a closed uniform model. The effects of $\mathrm{H}_{2}$ and syngas on the ignition performance of a natural gas/diesel engine were studied. The results showed that the ignition delay time of the methane/n-heptane mixture was prolonged after adding $\mathrm{H}_{2}$ in the range of medium and low temperatures. This was due to the fact that reaction $\mathrm{R} 3\left(\mathrm{OH}+\mathrm{H}_{2}=\mathrm{H}+\mathrm{H}_{2} \mathrm{O}\right)$ was an endothermic reaction, which consumed OH radicals and inhibited the ignition process. In the high-temperature range, adding $\mathrm{H}_{2}$ reduced the ignition delay time of the mixture system, which was because of the significant increase in the sensitivity coefficients of $\mathrm{R} 1\left(\mathrm{H}+\mathrm{O}_{2}=\mathrm{O}+\mathrm{OH}\right)$ and $\mathrm{R} 3$ and the generation of $\mathrm{OH}$ radicals. Therefore, the reduction in ignition delay caused by $\mathrm{H}_{2}$ addition in the high-temperature regions was mainly attributed to R3 and R1. In syngas, CO reduced the ignition delay time of methane/syngas/n-heptane. However, the addition of $\mathrm{CO}$ could reduce the importance of $\mathrm{R} 3$ in the reaction process-resulting in the weakening of the influence of $\mathrm{H}_{2}$ on ignition delay. This study can expand the theoretical basis of ignition characteristics of methane/n-heptane mixture with $\mathrm{H}_{2}$ and syngas under dual-fuel engine-relevant conditions.
\end{abstract}

\section{Introduction}

With the increasingly severe energy situation and the aggravation of the environmental crisis, the regulation of engine emission has become more and more strict and the research of natural gas (NG) engines has attracted more and more attention [1]. NG is a clean and efficient alternative fuel for engines, which almost does not contain sulfur, dust, or other harmful substances [2]. In addition, NG is rich in reserves and has been widely concerned by the international community.

The high octane number, the high ignition point, and the low activity of NG engines make it difficult to direct compression ignition, which usually needs external energy such as spark plug or diesel to ignite the fuel mixture. In the dual-fuel operation mode of NG/diesel, low-pressure NG is introduced into the intake manifold and then ignited by pilot diesel injected directly into the cylinder [3-5]. NG engines can use a higher compression ratio because of the high octane number of NG [6]. At the same time, earlier ignition time can be used to improve fuel efficiency, such as reactivity controlled compression ignition (RCCI) engine $[7,8]$. In this technology, low reactive fuel (e.g., gasoline, ethanol, or NG) is premixed into the cylinder by intake port, while high reactive fuel (e.g., diesel) is injected by early injection or multiple direct injections. In this way, the preparation time of the mixture can be prolonged and the fuel activity gradient can be formed in the cylinder, to improve the combustion efficiency and reduce emissions [9]. In addition, the NG fuel has a wide ignition limit and the engine can run in the condition of lean mixture. Compared with the traditional diesel engine, the combustion temperature of NG engine is 
significantly lower, which greatly reduces the emissions of soot, carbon dioxide, and nitrogen oxides (NOx) [10].

Despite these advantages, NG engines may have high cycle variability and high unburned hydrocarbon (HC) and carbon monoxide (CO) emissions under lean-burn conditions due to low flame speed and combustion efficiency $[11,12]$. Although the post-treatment systems such as selective catalytic reduction (SCR) [13] and oxidation catalyst [14] can be used, it is relatively expensive and increases the system complexity of NG engine, so it is difficult to be popularized and applied. Compared with NG, hydrogen $\left(\mathrm{H}_{2}\right)$ has high chemical activity. $\mathrm{H}_{2}$ seems to be a promising alternative fuel for internal combustion engines [15]. $\mathrm{H}_{2}$ is an ideal fuel combined with natural gas because of its wide flammability limit, which can make up for the limited leanburn ability and slow combustion speed of NG [16]. In addition, $\mathrm{H}_{2}$ is a kind of carbon-free fuel, and it can reduce the carbon emission of compression ignition engines. $\mathrm{H}_{2}$ and reformer gas (syngas includes $\mathrm{H}_{2}$ and $\mathrm{CO}$ ) have been considered as suitable blended fuels for internal combustion engine applications [17]. At present, many scholars are studying the preparation and combustion of syngas in internal combustion engines [18]. Flavio et al. [19] studied the advantages of diesel reforming in dual-fuel combustion strategy using three different reforming processes: partial oxidation reforming, steam reforming, and autothermal reforming. They found that the net efficiency of the engine could be improved by reforming the fuel. To improve engine fuel economy and reduce emissions, Sail et al. [20] conducted catalytic reforming of ethanol fuel to obtain a mixture containing $\mathrm{H}_{2}, \mathrm{CO}$, and $\mathrm{CH}_{4}$. The results show that the engine performance can be improved, and the emission can be reduced by mixing the reforming products $\mathrm{H}_{2}, \mathrm{CO}$, and $\mathrm{CH}_{4}$ with ethanol diesel. Guo et al. [21] numerically simulated the combustion and emission characteristics of homogeneous charge compression ignition engine. The research shows that hydrogen has dilution and chemical effect on the combustion stage of n-heptane fueled engine, especially the dilution effect. Geng et al. [22] studied the effect of n-heptane reforming components on combustion characteristics. They found that low-temperature fuel reforming combustion can reduce soot generation. Zhu et al. [23] studied the potential of cylinder thermal chemical fuel reforming (TFR) to improve engine performance. They found that TFR has the potential to further reduce emissions with higher compression ratio. In fact, the essential difference between syngas engine and NG/diesel dual-fuel engine is that the reaction path of fuel combustion can be changed by changing the initial conditions [24]. Therefore, it is quite important to know more about the ignition characteristics of $\mathrm{H}_{2}$ and $\mathrm{CO}$.

Although many works of literature on diesel and NG dual-fuel combustion have been published including the zero-dimensional model $[25,26]$ and the three-dimensional spray study [27, 28], however, previous studies mainly focused on the ignition characteristics of diesel and NG mixture when diesel is injected into NG. There is still an obvious gap in understanding the ignition and flame characteristics of $\mathrm{H}_{2}$ and $\mathrm{CO}$ additives in different combinations of dual-fuel blends. Therefore, it is quite important to understand the influence of syngas on the ignition characteristics and the chemical properties of the dual-fuel mixture. However, it is time-consuming and expensive to understand the influence of syngas addition on the emission and the combustion characteristics of the dualfuel engines only through experiments. Numerical simulation is a fast and economical method, which can help to understand the complicated combustion, spray, pollutant formation, and evaporation process in a dual-fuel engine [29].

Therefore, this work focuses on the effect of $\mathrm{H}_{2}$ and syngas on ignition properties under dual-fuel enginerelevant conditions. $\mathrm{N}$-heptane has a high cetane number and good chemical activity, so it can be used as a substitute for diesel [30]. NG is a mixture with methane as the main component, so methane is selected as the alternative fuel of NG [31]. The main purpose of this work was to use the chemical kinetic mechanism of n-heptane [32] to simulate the effect of syngas addition on the ignition characteristics of a dual-fuel engine. In addition, the new contribution of this work is to study the influence of the addition of syngas on the oxidation process of n-heptane/methane dual fuel from the low-temperature reaction path of $n$-heptane/methane. The reaction rate of production (ROP) and the sensitivity analysis under dual-fuel engine-relevant conditions were studied to explain the phenomenon in the simulation results. This work provides a reference for the research of dualfuel engine fuel reforming.

\section{Simulation Methods}

2.1. Mechanism Selection and Validation. In this study, the reduced chemical kinetic mechanism of n-heptane and different NG components developed by Hockett et al. [32] was selected. Then, it was called the CSU mechanism, which consisted of 141 species and 709 reactions. Due to the lack of chemical mechanism and experimental data of ignition and flame characteristics of more than three fuels, such as methane $/ \mathrm{H}_{2} / \mathrm{n}$-heptane and methane/syngas/n-heptane, this study only validated the ignition characteristics of single fuel and dual fuel under engine-relevant conditions. The ignition delay time was predicted using the ANSYS Chemkin 17.0 software simulation data [33]. The problem type was used to constrain the volume and solve the energy equation with the closed homogeneous model that calculates the ignition delay time.

Figure 1 shows the comparison between the experimental values and the CSU mechanism of n-heptane [34], methane [35], methane/n-heptane [36], methane/ $\mathrm{H}_{2}$ $[37,38]$, and $\mathrm{H}_{2} / \mathrm{CO}[39]$ in different operating conditions (temperature, pressure, equivalence ratio, and gas component content). It can be seen that the predicted values of ignition delay agree well with the experimental values in different temperature, pressure, and equivalence ratio ranges, which indicates that the current CSU mechanism can reproduce the ignition characteristics of n-heptane, methane, $\mathrm{H}_{2}$, and syngas. 

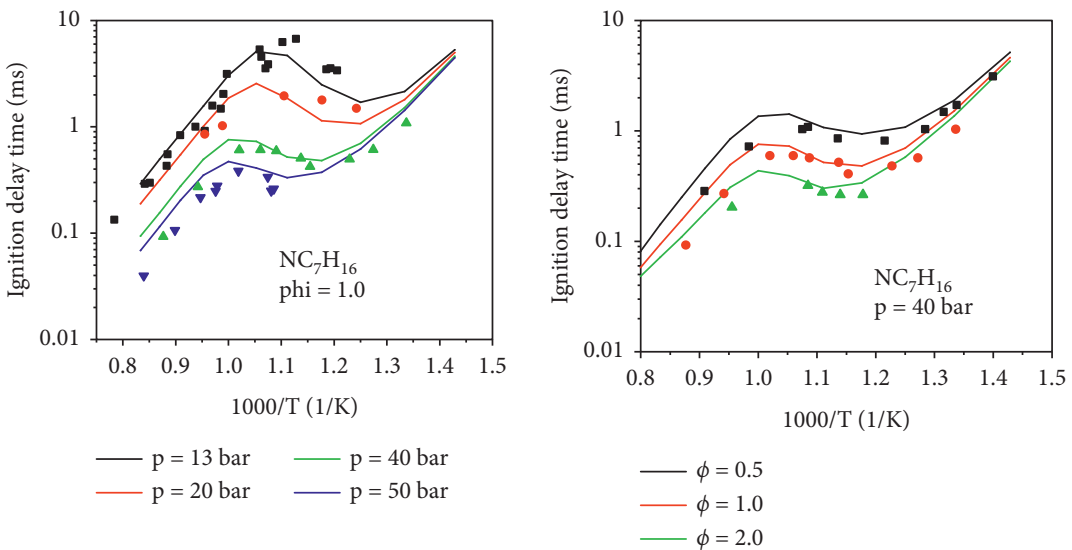

(b)
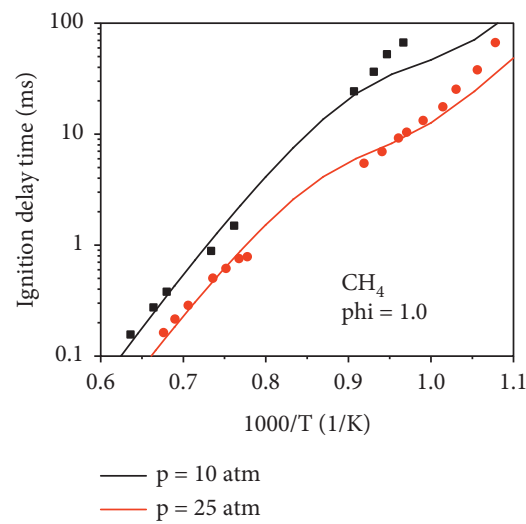

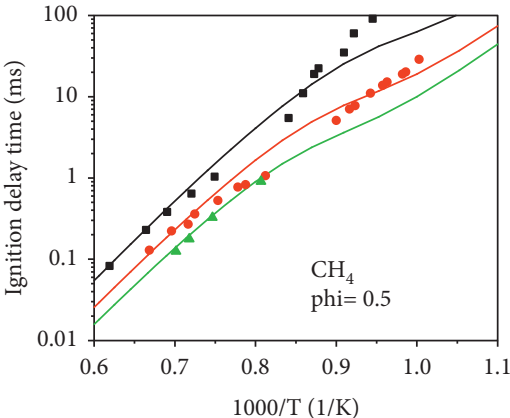

- $\mathrm{p}=10$ atm

- $\mathrm{p}=25 \mathrm{~atm}$

$\mathrm{p}=44 \mathrm{~atm}$

(c)

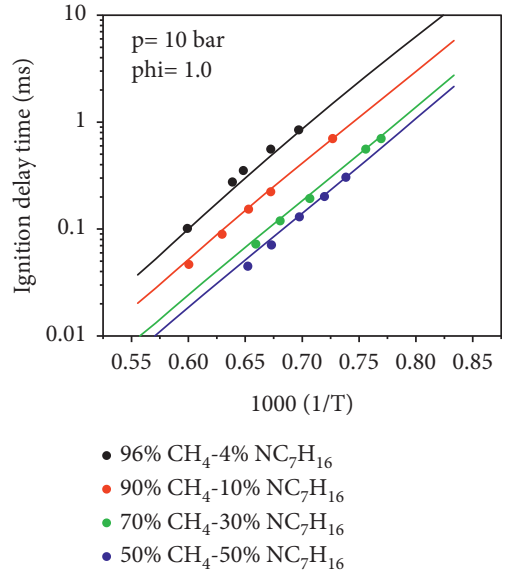

(e)

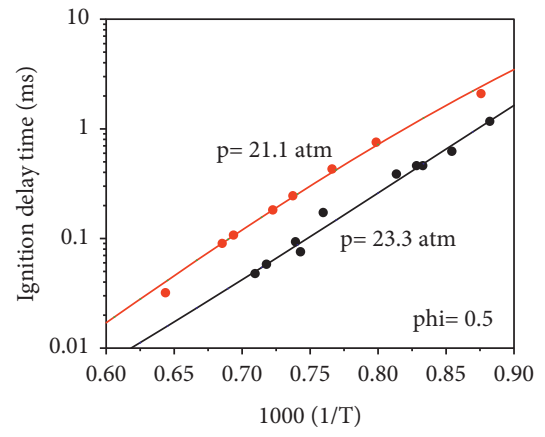

- $60 \% \mathrm{CH}_{4}-40 \% \mathrm{H}_{2}$ - $80 \% \mathrm{CH}_{4}-20 \% \mathrm{H}_{2}$ (d)

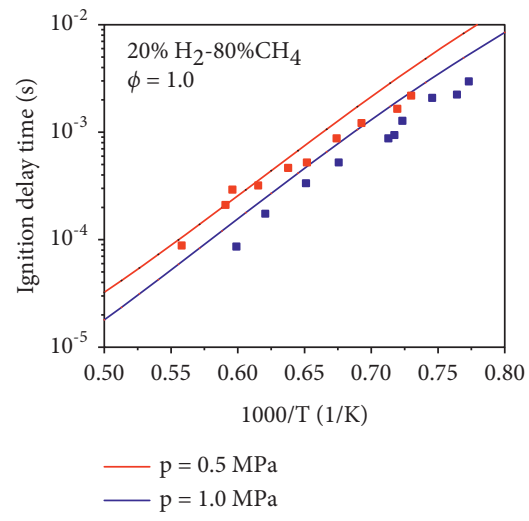

(g)

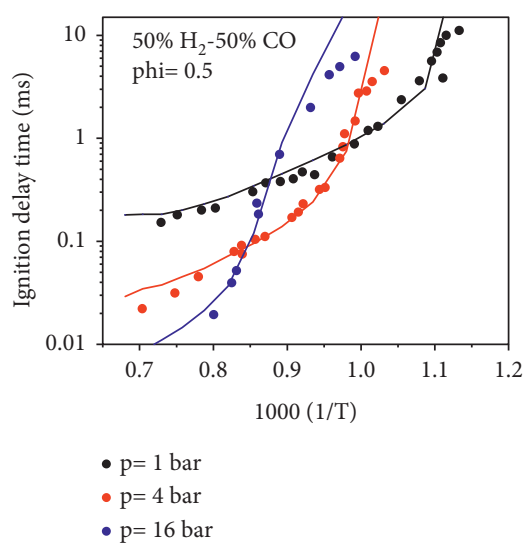

(h)

Figure 1: Ignition delay time validation for multiple conditions of $\mathrm{n}$-heptane [34], methane [35], methane/n-heptane [36], methane/ $\mathrm{H}_{2}$ [37, 38], and $\mathrm{H}_{2} / \mathrm{CO}$ [39]. Solid line: simulation; symbols: experiment.

Figure 2 shows the comparison between the two different detailed mechanisms and the CSU mechanism ignition delay times for single-fuel combustion of $\mathrm{H}_{2}$, carbon monoxide, and methane at $p=80$ bar and $\phi=0.5$. The two detailed mechanisms are the n-pentane mechanism developed by Healy et al. [40] at the National University of Ireland Galway (NUIG) and the $\mathrm{n}$-heptane mechanism developed by Curran et al. [41] at Lawrence Livermore National Laboratory
(LLNL), respectively. Under engine-related conditions, the temperature is usually higher than $900 \mathrm{~K}$ and the pressure is usually higher than 40 bar [8]. The ignition delay time of these single fuels is longer than that of $\mathrm{n}$-heptane. Compared with the ignition delay time of $\mathrm{H}_{2}$, methane, and carbon monoxide, the ignition delay time of carbon monoxide is the shortest. For $\mathrm{n}$-heptane, the negative coefficient temperature (NCT) behavior usually occurs in the middle-temperature 


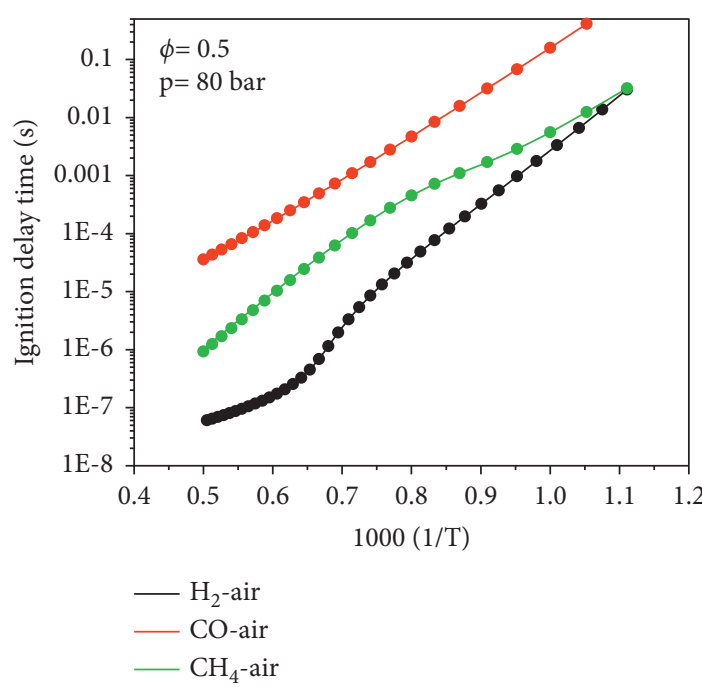

(a)

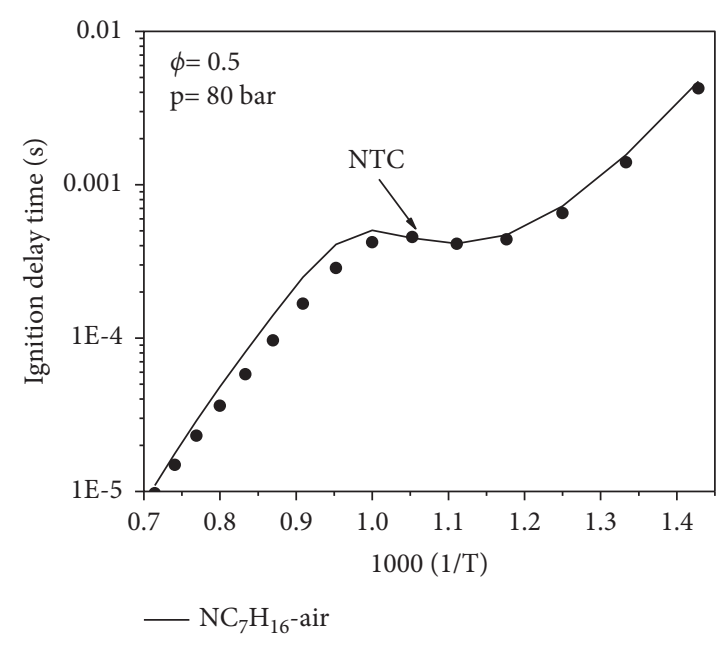

(b)

FIgURE 2: Comparison between the ignition delay time of the CSU mechanism (solid line) and the detailed mechanism (symbol) for single fuel at $p=80$ bar and $\phi=0.5$. (a) NUIG [40] mechanism and CSU mechanism. (b) LLNL [41] mechanism and CSU mechanism.

region. To study the ignition characteristics of a dual-fuel engine with $\mathrm{H}_{2}$ and syngas, the ignition process of dual fuel will be discussed in this study for the addition of $\mathrm{H}_{2}$ and syngas at different temperatures.

2.2. Numerical Settings. In this study, the influence of the $\mathrm{H}_{2}$ and syngas addition of dual fuel on ignition delay is analyzed, so the correlation equation is described by the mixture of $\mathrm{n}$-heptane, methane, $\mathrm{H}_{2}$, syngas, and air. Assume that the molar composition percentages of $\mathrm{N}_{2}$ and $\mathrm{O}_{2}$ in the air are $79 \%$ and $21 \%$, respectively. The equivalence ratio of hydrocarbon fuel is defined as follows:

$$
\phi=\frac{\left(X_{\text {Fuel }} / X_{\text {Air }}\right)}{\left(X_{\text {Fuel }} / X_{\text {Air }}\right)_{\text {stoic }}} \text {. }
$$

Here, the fuel molar ratio is defined using the parameter $\alpha$.

$$
\alpha=\frac{X_{\mathrm{add}}}{X_{\mathrm{CH}_{4}}},
$$

where $X_{\text {add }}$ represent the $X_{\mathrm{H}_{2}}\left(\mathrm{H}_{2}\right.$ mole fractions $)$ and $X_{\mathrm{H}_{2}}+$ $X_{\mathrm{CO}}$ (syngas mole fractions), respectively. The sum of fuel and air is unity and defined as a mole fraction $X_{\text {Fuel }}+X_{\text {Air }}=1$.

To analyze the ignition process of multicomponent fuel with different $\mathrm{n}$-heptane contents, four different $\mathrm{n}$-heptane equivalence ratios $0-0.5\left(\beta=X_{\mathrm{NC}_{7} \mathrm{H}_{16}} / X_{\mathrm{O}_{2}}=0,2.436 \times 10^{-3}\right.$, $2.112 \times 10^{-2}$, and $4.545 \times 10^{-2}$ ) under engine-relevant conditions were established. Therefore, the effect of $\mathrm{H}_{2}$ and syngas on the ignition delay time of methane/n-heptane can be clearly analyzed by changing the ratio of $\mathrm{H}_{2}$ and syngas to methane.

\section{Results and Discussion}

3.1. Methane and n-Heptane Blend. Before studying the effect of $\mathrm{H}_{2}$ and syngas addition on the dual fuel, the effect of methane addition on the ignition characteristics of n-heptane should be understood. Figure 3 shows the ignition delay time versus the initial temperature. It can be seen from Figure 3 that the ignition process of methane/nheptane dual fuel shows a certain NTC behavior at the medium- and low-temperature ranges. Xiao and Aggarwal [42] reported that the oxidation of large alkanes is characterized by two-stage ignition and NTC behavior. When the n-heptane mixing ratio decreases, the ignition delay time increases, and the NTC behavior of the total ignition delay time tends to be flat. The ignition delay time of methane/n-heptane dual-fuel changes nonlinearly with the increase in methane mixing ratio, and the changing trend is consistent and increases with the increase in methane mixing ratio. This also shows that the ignition time of n-heptane is prolonged after adding methane, and the changing trend is large in the range of medium and low temperatures. With the increase in initial pressure and equivalence ratio, the addition of methane has the same effect on ignition delay of n-heptane.

To discuss the influence of different compositions and pressure on the ignition delay time under dual-fuel combustion conditions, the normalized ignition delay time in this study is defined using the parameter $\tau_{\text {norm }}$.

$$
\tau_{\text {norm }}=\frac{\tau_{d f}}{\tau_{\mathrm{NC}_{7} \mathrm{H}_{16}}},
$$

where $\tau_{d f}$ represents the ignition delay time of dual fuel and $\tau_{\mathrm{NC}_{7} \mathrm{H}_{16}}$ represents the ignition delay time of $\mathrm{n}$-heptane. 


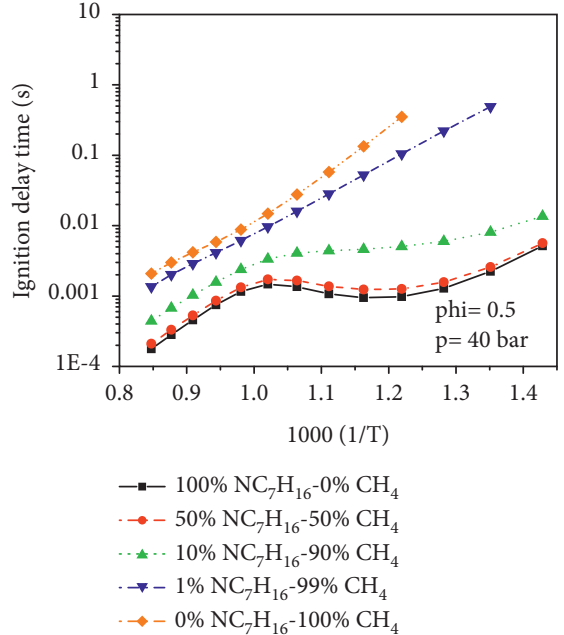

(a)

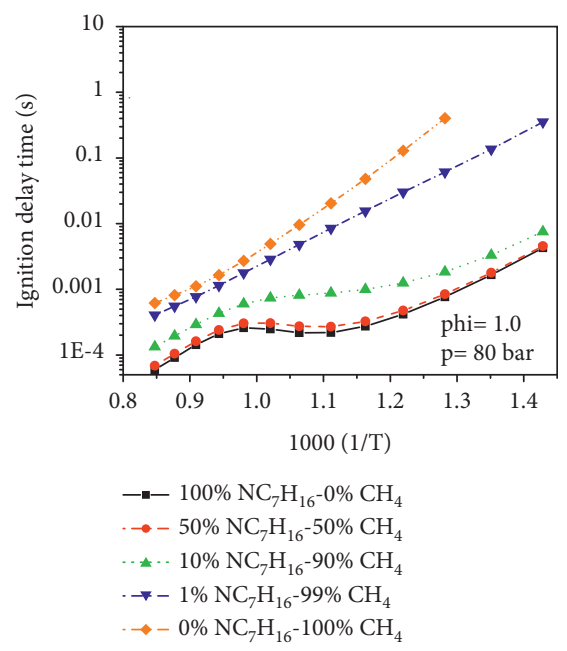

(d)

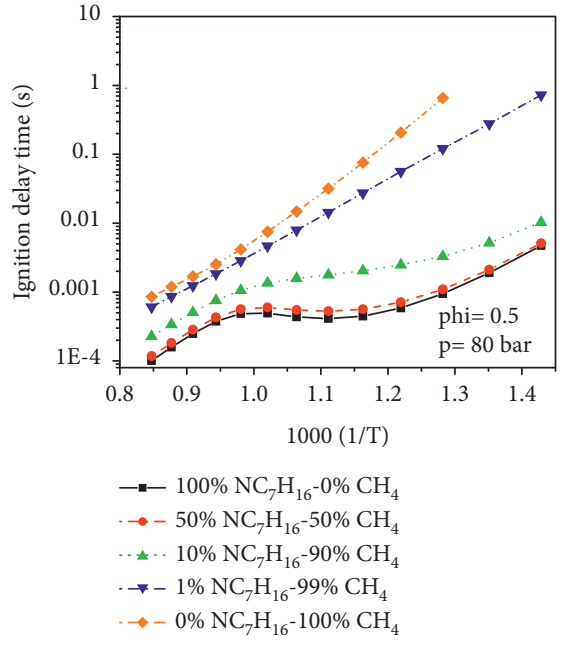

(b)

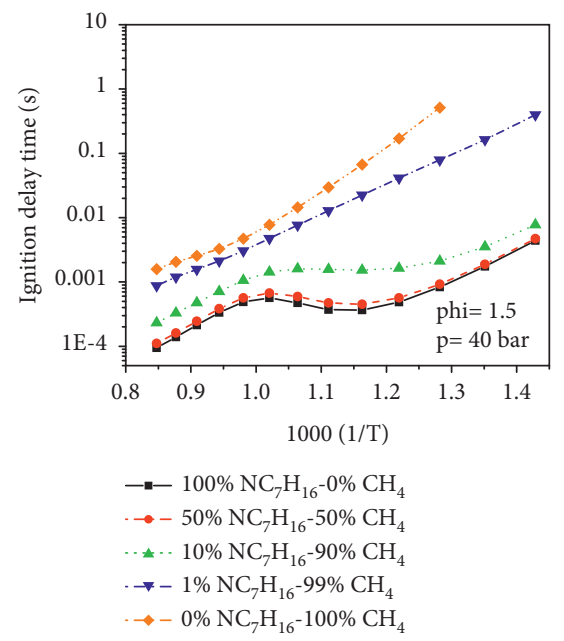

(e)

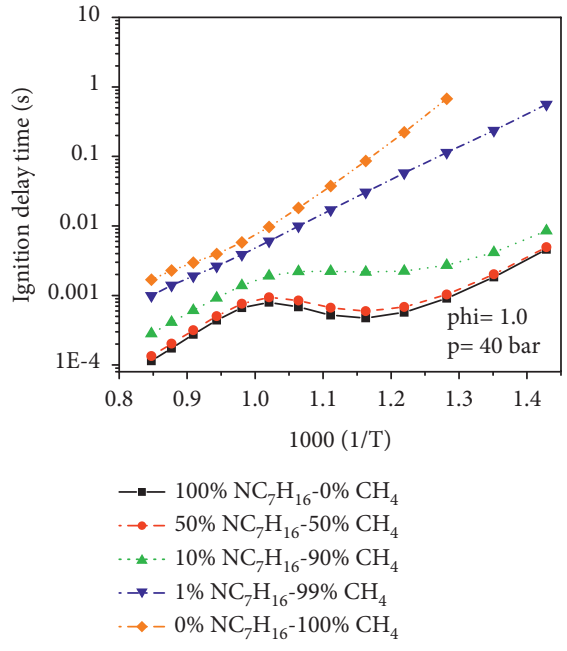

(c)

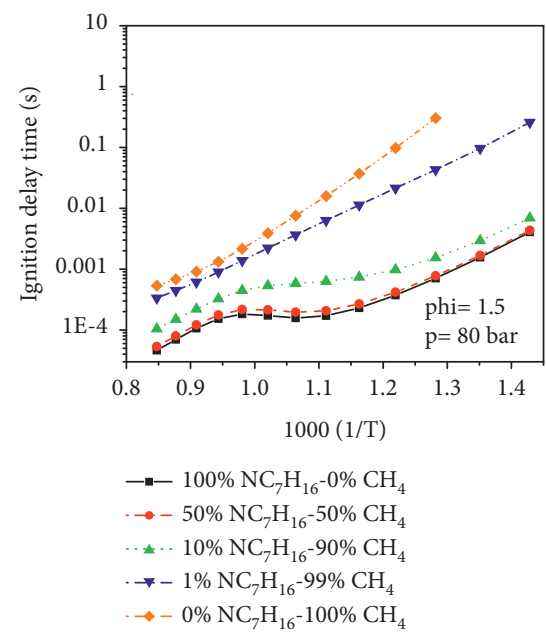

(f)

FIgURE 3: Ignition delay time of different methane/n-heptane mixing ratios at $p=40$ bar, 80 bar, and different equivalence ratios.

Figure 4 shows the normalized ignition delay time of different methane/n-heptane mixing ratios at $p=40 \mathrm{bar}, 80$ bar, and different equivalence ratios. It can be seen that the change in equivalence ratio has a greater influence on ignition delay time in the range of medium and low temperatures, while it has a little influence on ignition delay in the condition of high temperature. In the middle- and lowtemperature regions, the normalized ignition delay time of the lean mixture is significantly higher than that of the stoichiometric mixture and the rich mixture. Ghaderi Masouleh et al.'s [26] research results support this view. Moreover, the normalized ignition delay time increases with the increase in methane content, especially at low.

Figure 5 shows the species and temperature evolution of different methane $/ \mathrm{n}$-heptane mixing ratios at $T=900 \mathrm{~K}$, $\phi=1$, and $p=40$ bar. It can be seen that the accumulation of $\mathrm{HO}_{2}$ mainly occurred in the low-temperature reaction stage and the accumulation of $\mathrm{H}_{2} \mathrm{O}_{2}$ reaches the peak in the hightemperature exothermic stage. N-heptane decomposes earlier than methane and produces a lot of free radicals. This can be due to the weak bond of n-heptane molecules, which leads to faster decomposition. This explains that $n$-heptane can be used as a pilot fuel to ignite methane. Furthermore, the concentration of free radicals decreases and the ignition delay time increases with the increase in methane content, which is a good explanation for the previous study.

3.2. Effect of $\mathrm{H}_{2}$ Addition. Figure 6 shows the ignition delay time changes in the methane $/ \mathrm{H}_{2} / \mathrm{n}$-heptane system with varying $\alpha$. As mentioned in the previous numerical setting section, changing $\beta$ will change the equivalence ratio of $\mathrm{n}$-heptane, while changing $\alpha$ will change the mole fraction ratio of methane to $\mathrm{H}_{2}$. It can be seen that when the $\beta$ value increases, the NTC behavior becomes more obvious and the ignition delay time decreases. However, the change in ignition delay time with the initial temperature at different $\alpha$ values shows that the influence of initial temperature on ignition delay is obvious. At low temperatures, ignition delay time increases gradually with the increase in $\mathrm{H}_{2}$ content and 


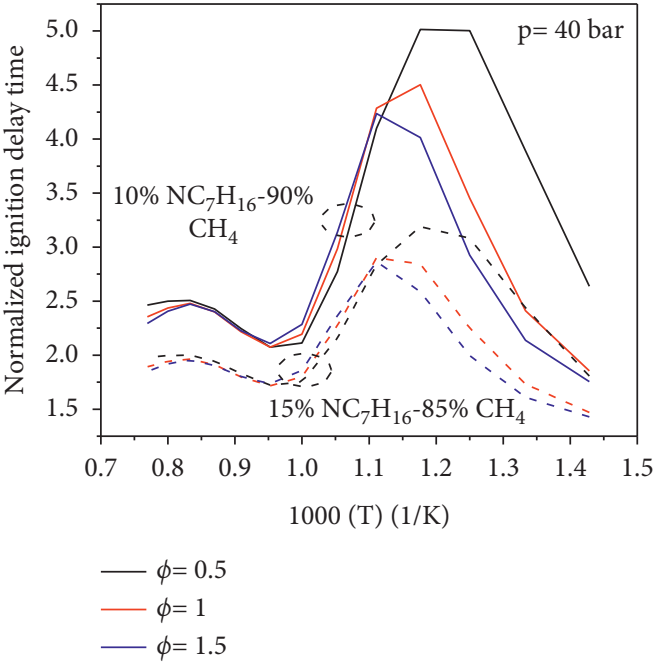

(a)

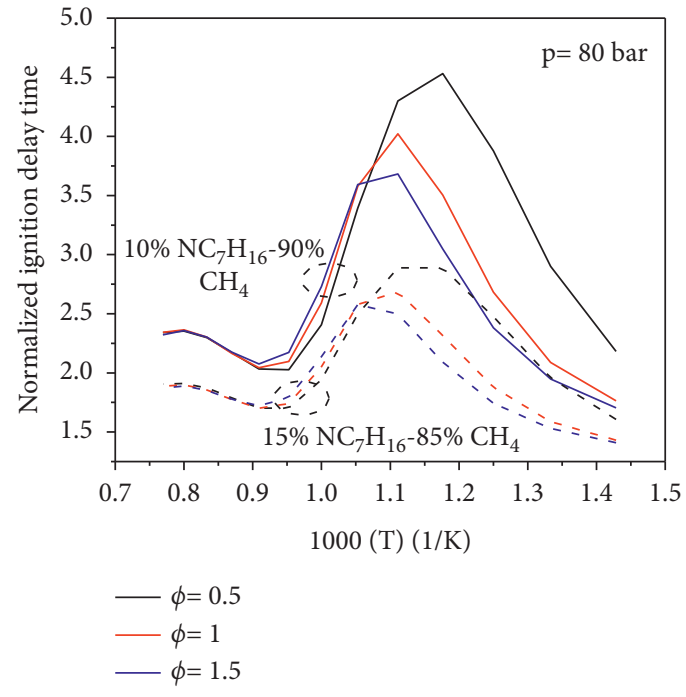

(b)

FIgURE 4: Normalized ignition delay of different methane/n-heptane mixing ratios at $p=40$ bar, 80 bar, and different equivalence ratios.

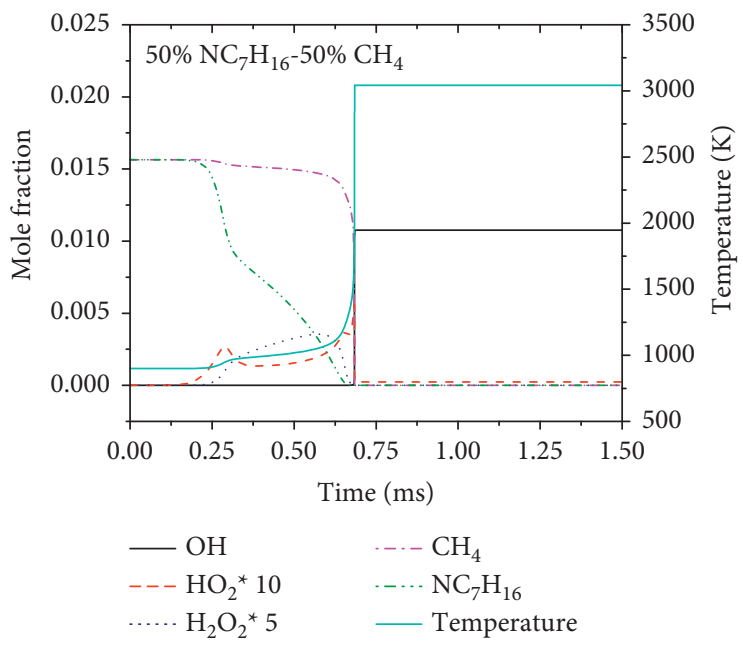

(a)

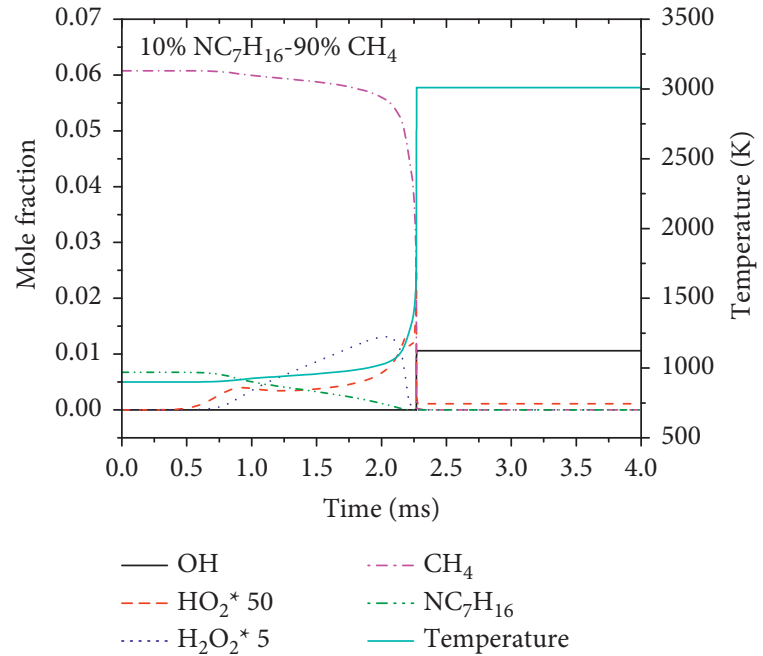

(b)

FIgURE 5: Species and temperature evolution of different methane/n-heptane mixing ratios at $T=900 \mathrm{~K} \phi=1$, and $p=40 \mathrm{bar}$.

vice versa at high temperatures. When the $\mathrm{n}$-heptane equivalence ratio increases, the influence of methane and $\mathrm{H}_{2}$ on ignition delay time weakens. However, the effect of large amounts of $\mathrm{H}_{2}$ addition on ignition delay is obviously enhanced. To better understand the effect of initial temperature on the ignition process, an evaluation of thermal and species, ROP, and sensitivity analysis will be carried out to explain the phenomenon in the simulation results.

Figure 7 shows the time evolution of reactants and some important free radicals at $\beta=4.545 \times 10^{-2}$ and initial temperatures of $900 \mathrm{~K}$ and $1000 \mathrm{~K}$, respectively. From this point on, the ignition delay time is defined as the time when $\mathrm{OH}$ radical reaches the maximum mole fraction. From Figure 7 , the ignition delay time increases with the increase in $\mathrm{H}_{2}$ fraction in the mixture when the initial temperature is $900 \mathrm{~K}$ and vice versa when the initial temperature is $1000 \mathrm{~K}$. The low-temperature reaction of $n$-heptane generates an $\mathrm{HO}_{2}$ radical, and there are two peaks of the $\mathrm{HO}_{2}$ radicals, which gradually decrease after the first peak and $\mathrm{HO}_{2}$ transforms into $\mathrm{H}_{2} \mathrm{O}_{2}$. However, $\mathrm{H}_{2}$ decomposes before methane, consuming $\mathrm{OH}$ radicals, and the concentration of $\mathrm{H}_{2} \mathrm{O}_{2}$ decreases sharply forming $\mathrm{OH}$ radicals. When the initial temperature is $1000 \mathrm{~K}$, the two-stage ignition characteristics disappear.

Figure 8 shows the effect of initial temperature and $\alpha$ on temperature and intermediate radical mole fraction evolution at $\beta=4.545 \times 10^{-2}, p=40 \mathrm{bar}$, and $\phi=1$. It is worth noting that $\mathrm{RO}_{2}$ stands for $\mathrm{C}_{7} \mathrm{H}_{15} \mathrm{O}_{2}$, which is also a sign of ignition delay time in the first stage of the low-temperature reaction. It can be seen that the ignition delay changes from 

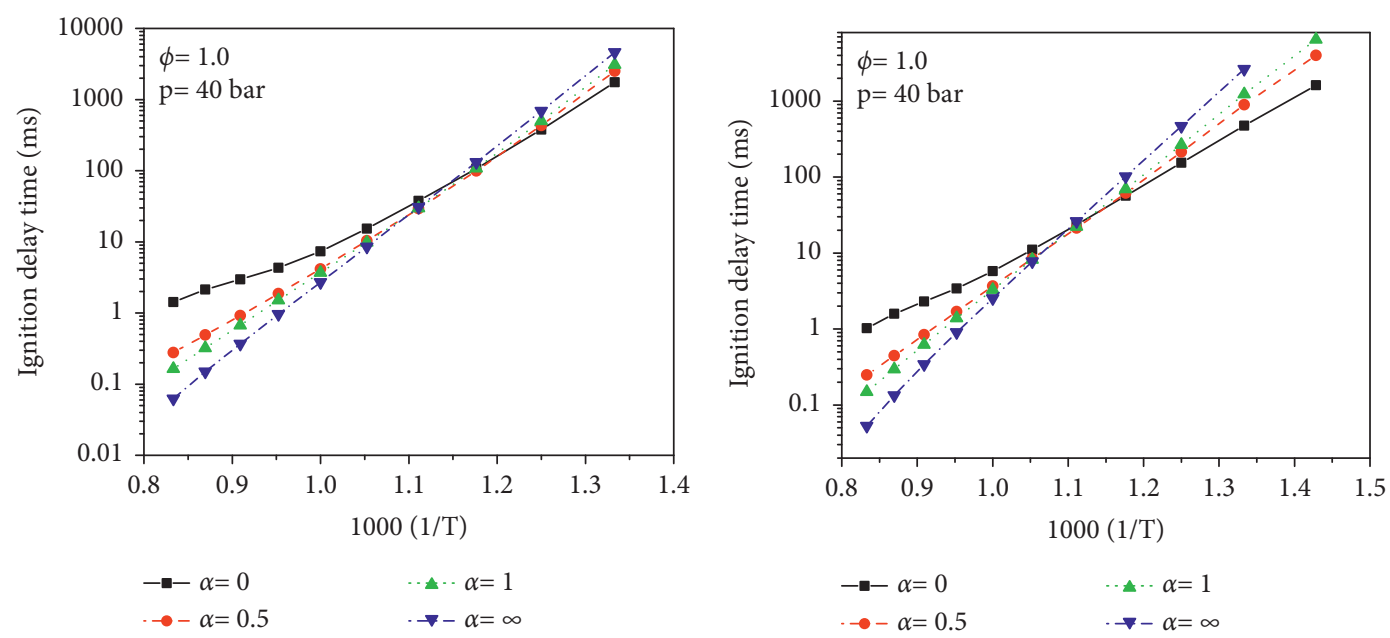

(a)
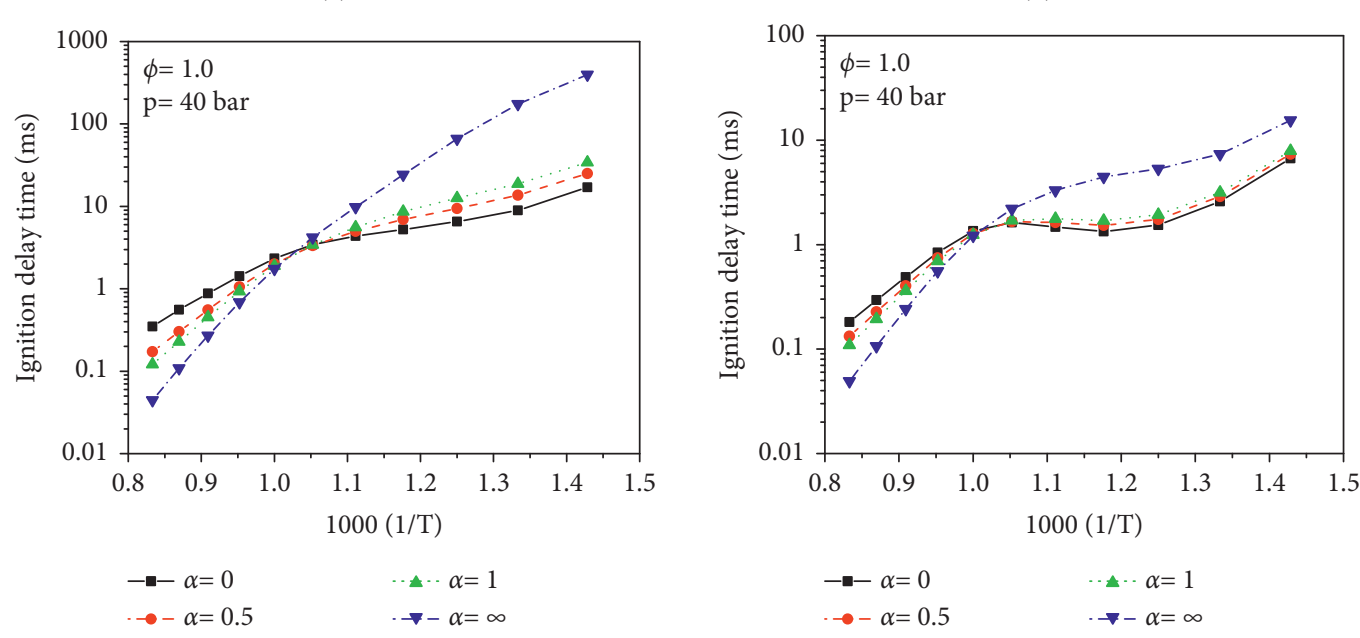

(c)

(d)

Figure 6: Ignition delay time of different $\alpha$ values for methane $/ \mathrm{H}_{2} / \mathrm{n}$-heptane mixtures at $\beta=0,2.436 \times 10^{-3}, 2.112 \times 10^{-2}$, and $4.545 \times 10^{-2}$, respectively.

two stages to one stage with the increase in initial temperature. It can also be seen from the temperature curve that when the initial temperature is $900 \mathrm{~K}$, the ignition delay time increases with the increase in $\mathrm{H}_{2}$ content, and combustion temperature and free radical concentration are lower in the initial combustion stage. However, when the initial temperature is greater than $1000 \mathrm{~K}$, the ignition delay time advances with the increase in $\mathrm{H}_{2}$ content and the ignition delay time is more advanced with the increase in temperature. In the initial combustion stage, the combustion temperature and free radical concentration are higher. Furthermore, the amplitude of the second peak of $\mathrm{HO}_{2}$ and the corresponding $\mathrm{OH}$ peak becomes larger. In all cases, the addition of $\mathrm{H}_{2}$ will increase the final temperature of the reaction system.

Figure 9 shows the ratio of the second-stage ignition delay time at the different initial temperatures. When the initial temperature is in the low-temperature region, the ignition delay time increases with the increase in $\mathrm{H}_{2}$ content. When the temperature is in the high-temperature region, the ignition delay time advances with the increase in $\mathrm{H}_{2}$ content. These aspects will be further studied in the next sensitivity analysis. It can be seen that in the high-temperature region, the ratio of delayed ignition time in the second stage is closer to 1 with the increase in the $n$-heptane equivalence ratio. The effect of n-heptane on the ignition delay of the system has been discussed in Figure 6, which indicates that the free radicals of highly reactive fuel decomposed at low-temperature reaction have a great effect on the ignition delay.

Before sensitivity analysis, the ignition process and reaction path of $n$-heptane need to be analyzed briefly. Considering the initial temperature range of this study, n-heptane is mainly oxidized at the medium- and lowtemperature regions. Firstly, n-heptane occurs via $\mathrm{H}$ atom abstraction to form alkyl ( $\mathrm{R}$ ) radicals and then $\mathrm{R}$ radical is oxidized to form alkylperoxy $\left(\mathrm{RO}_{2}\right)$ radicals, which is isomerized to form various isomers such as alkyl hydroperoxy (QOOH) radical. Then, the second oxidation reaction is carried out to form peroxy alkyl hydroperoxy $\left(\mathrm{QOOHO}_{2}\right)$ radical and later the decomposition reaction is carried out to 


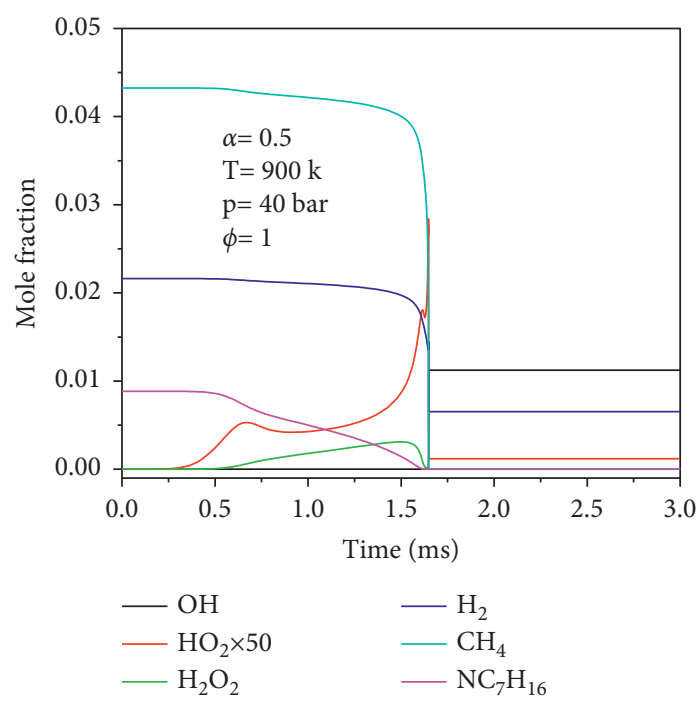

(a)

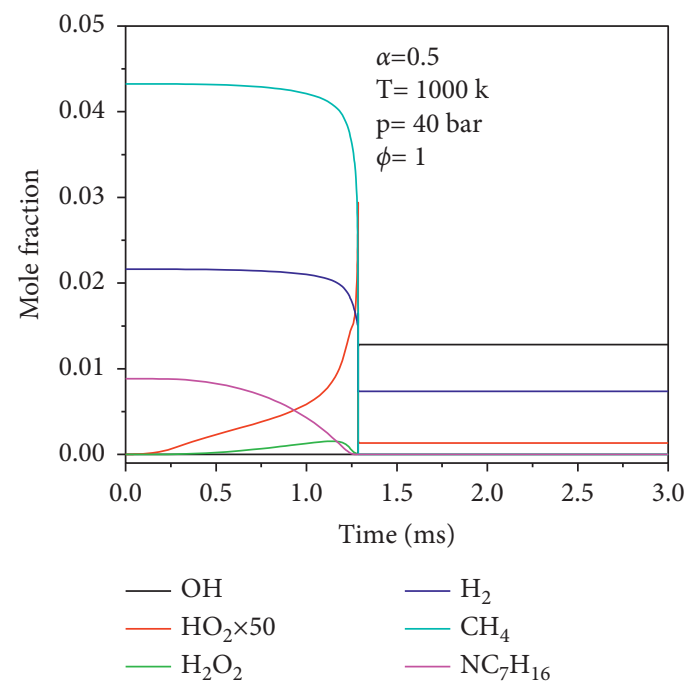

(c)

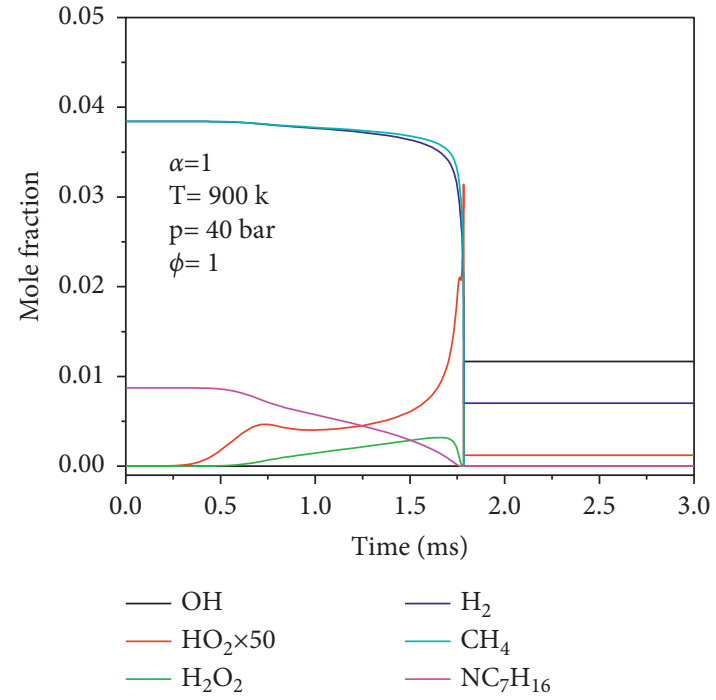

(b)

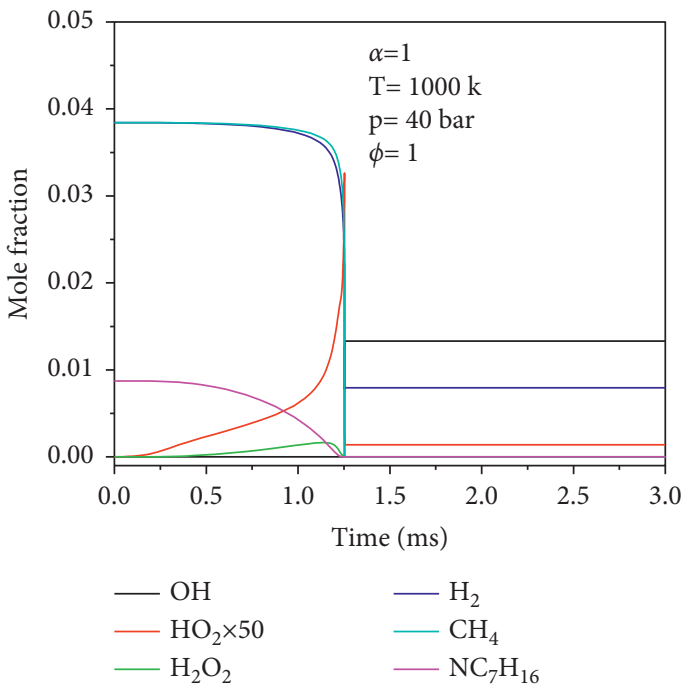

(d)

Figure 7: Effect of initial temperature and $\alpha$ on species evolution for methane $/ \mathrm{H}_{2} / n$-heptane mixtures at $\beta=4.545 \times 10^{-2}, p=40$ bar, and $\phi=1$.

form ketohydroperoxide $\left(\mathrm{NC}_{7} \mathrm{KET}\right)$ and $\mathrm{OH}$ radical. This is the complete oxidation process of $n$-heptane. On the basis of the above discussion, the first 16 representative reactions in Table 1 [43, 44], which are also very important in the previous sensitivity analysis, are selected for sensitivity analysis under three different $\alpha$ values.

To explain the influence of different mixing ratios of methane $/ \mathrm{H}_{2} / \mathrm{n}$-heptane on the ignition process in this study, three typical mixing ratios were analyzed and the reaction sensitivity analysis was carried out for the important reactions at 40 bar. The sensitivity coefficient $S_{i}$ is defined as follows:

$$
S_{i}=\frac{\tau\left(2 k_{i}\right)-\tau\left(0.5 k_{i}\right)}{1.5 \tau\left(k_{i}\right)},
$$

where $S_{i}$ is the sensitivity coefficient of ignition delay time, $\tau$ is the ignition delay time, and $k_{i}$ is the pre-exponential factor of the $i_{\text {th }}$ reaction. A negative $S_{i}$ indicates that the reaction can promote the ignition of the fuel, whereas a positive $S_{i}$ indicates that the reaction inhibited the ignition of the fuel.

Figure 10(a) shows the sensitivity analysis of the important reactions for ignition of methane $/ \mathrm{H}_{2} / \mathrm{n}$-heptane mixtures in the NTC region. For the case of $\alpha=0$, the main hydrocarbon reactions in the NTC region are R547-R670 when the initial temperature is $900 \mathrm{~K}$. For the case of $\alpha=0.5$ and 1 , the results show that the sensitivity to the above reactions is basically unchanged after adding $\mathrm{H}_{2}$. More importantly, Figure 10 shows that the effect of R3 is more and more obvious, and the reaction inhibits the ignition of the fuel. With the increase in $\mathrm{H}_{2}$ addition, the ignition rate in the NTC region slows down. It should be noted that the reaction is endothermic and consumes $\mathrm{OH}$ radicals. Therefore, the increase in ignition delay caused by the addition of $\mathrm{H}_{2}$ in the NTC region is mainly attributed to $\mathrm{R} 3$. 


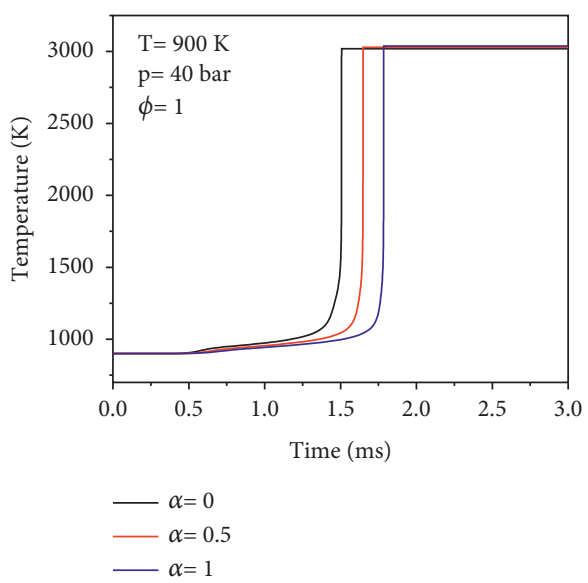

(a)

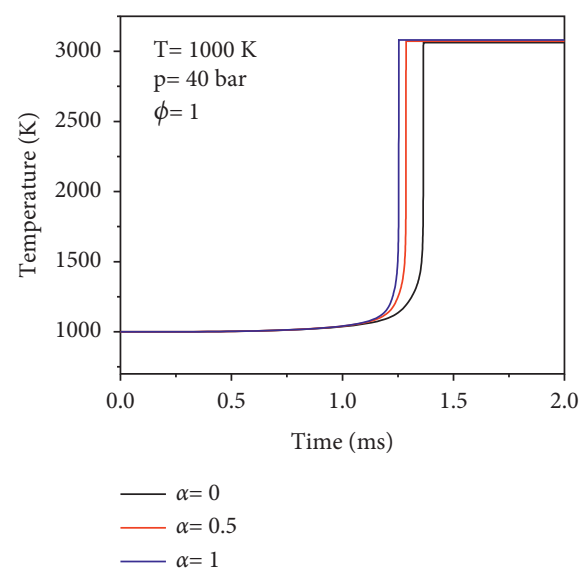

(c)

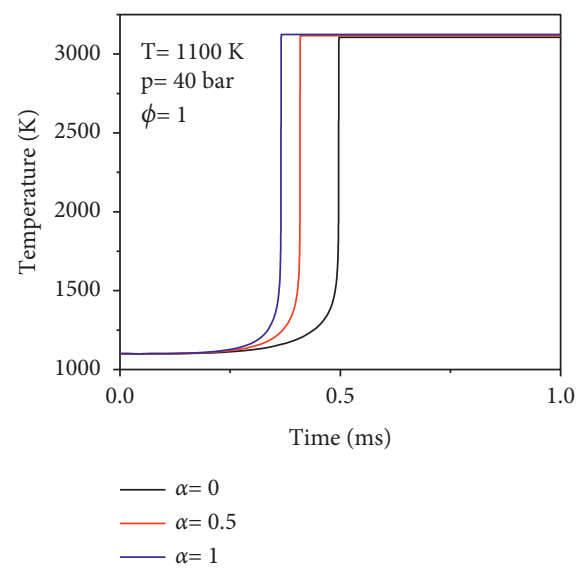

(e)

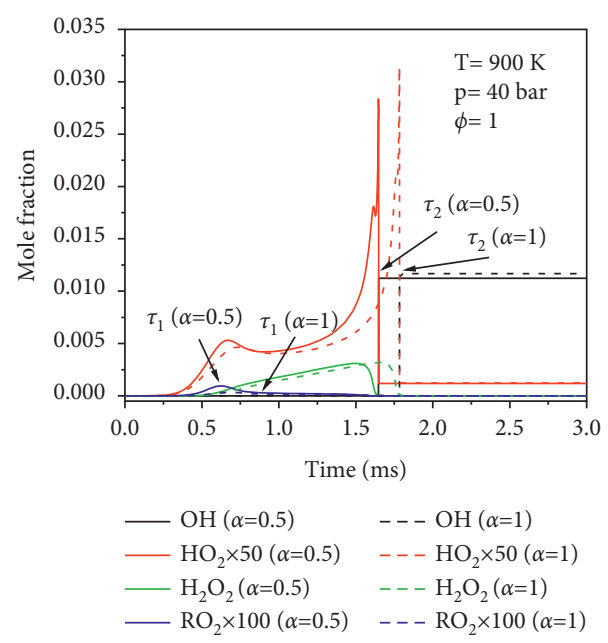

(b)

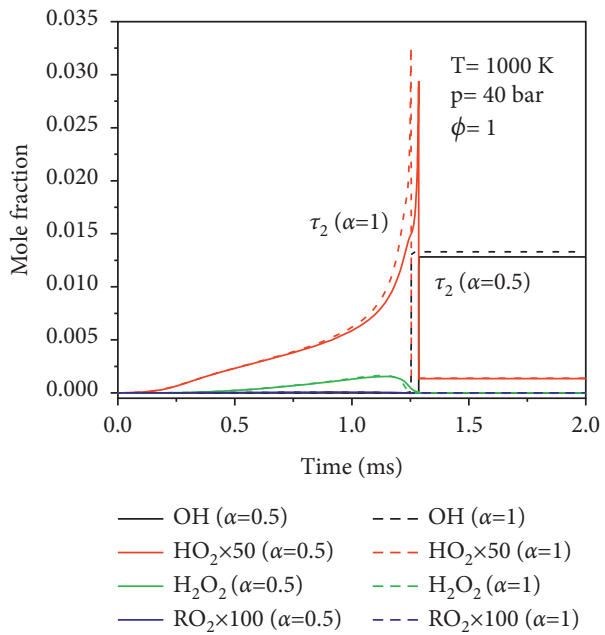

(d)

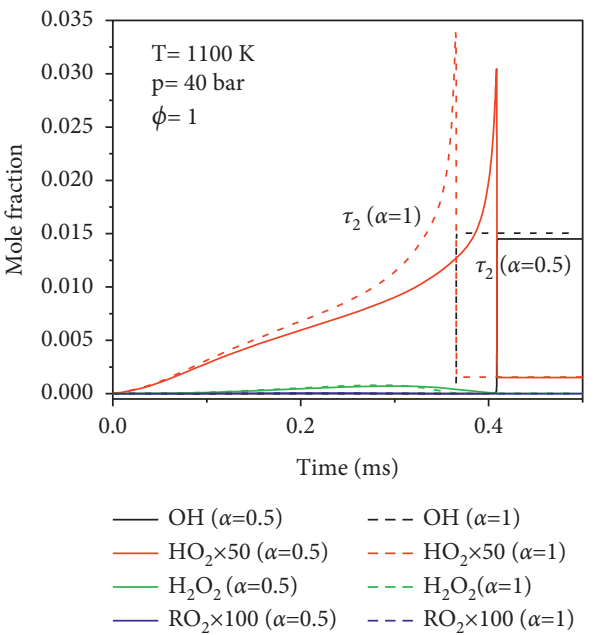

(f)

FiguRE 8: Effect of initial temperature and $\alpha$ on temperature and intermediate radical mole fraction evolution for methane/ $\mathrm{H}_{2} / \mathrm{n}$-heptane mixtures at $\beta=4.545 \times 10^{-2}, p=40$ bar, and $\phi=1$. 


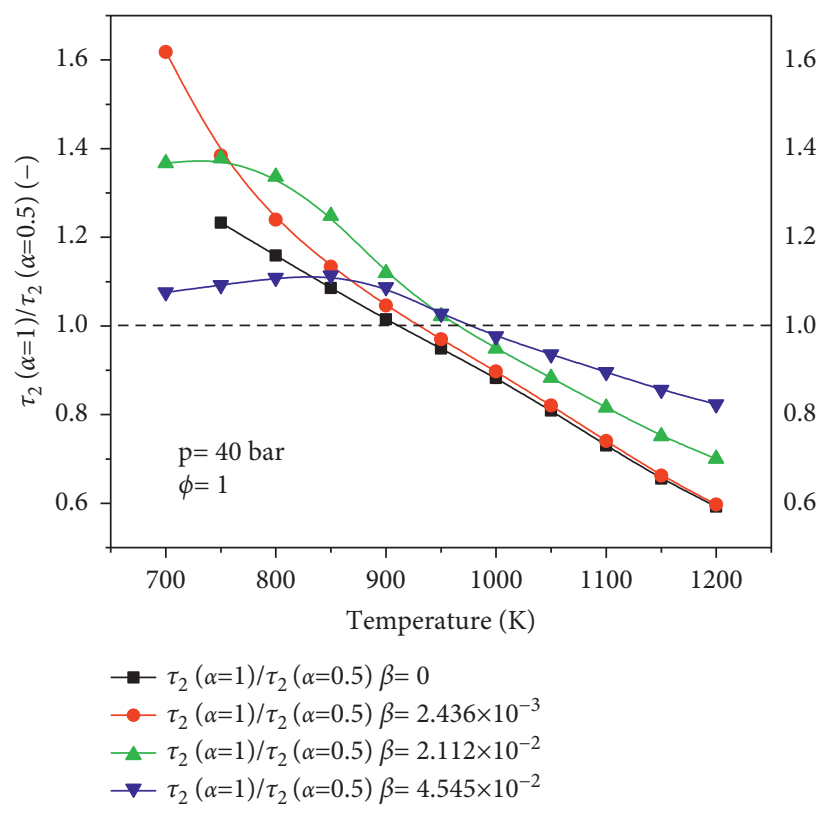

Figure 9: Ratio of the second-stage ignition delay time of different initial temperatures for methane $/ \mathrm{H}_{2} / \mathrm{n}$-heptane mixtures at $p=40$ bar and $\phi=1$.

TABLE 1: Important reactions for the ignition processes of methane/ $\mathrm{H}_{2} /$ n-heptane mixtures.

\begin{tabular}{lcc}
\hline Number & Elementary reactions & $\mathrm{A}$ \\
\hline $\mathrm{R} 1$ & $\mathrm{H}+\mathrm{O}_{2}=\mathrm{O}+\mathrm{OH}$ & $3.547 E+15$ \\
$\mathrm{R} 3$ & $\mathrm{OH}+\mathrm{H}_{2}=\mathrm{H}+\mathrm{H}_{2} \mathrm{O}$ & $2.16 E+8$ \\
$\mathrm{R} 9$ & $\mathrm{H}+\mathrm{O}_{2}(+\mathrm{M})=\mathrm{HO}_{2}(+\mathrm{M})$ & $1.475 E+12$ \\
$\mathrm{R} 16$ & $\mathrm{H}_{2} \mathrm{O}_{2}(+\mathrm{M})=2 \mathrm{OH}(+\mathrm{M})$ & $2.951 E+14$ \\
$\mathrm{R} 78$ & $\mathrm{CH}_{4}+\mathrm{OH}=\mathrm{CH}_{3}+\mathrm{H}_{2} \mathrm{O}$ & $5.83 E+4$ \\
R85 & $\mathrm{CH}_{3}+\mathrm{HO} 2=\mathrm{CH}_{4}+\mathrm{O}_{2}$ & $1.16 E+5$ \\
R496 & $\mathrm{NC}_{7} \mathrm{H}_{16}+\mathrm{OH}=\mathrm{C}_{7} \mathrm{H}_{15}-1+\mathrm{H}_{2} \mathrm{O}$ & $2.57 E+7$ \\
R501 & $\mathrm{NC}_{7} \mathrm{H}_{16}+\mathrm{HO}_{2}=\mathrm{C}_{7} \mathrm{H}_{15}-2+\mathrm{H}_{2} \mathrm{O}_{2}$ & 126.4 \\
R509 & $\mathrm{NC}_{7} \mathrm{H}_{16}+\mathrm{O}_{2}=\mathrm{C}_{7} \mathrm{H}_{15}-2+\mathrm{HO}_{2}$ & $2.8 E+13$ \\
R547 & $\mathrm{C}_{7} \mathrm{H}_{15}-4=\mathrm{C}_{2} \mathrm{H}_{5}+\mathrm{C}_{5} \mathrm{H}_{10}-1$ & $1.143 E+18$ \\
R629 & $\mathrm{C}_{7} \mathrm{H}_{15} \mathrm{O}_{2}-2=\mathrm{C}_{7} \mathrm{H}_{14}-1+\mathrm{HO}_{2}$ & $1.0075 E+43$ \\
R632 & $\mathrm{C}_{7} \mathrm{H}_{15} \mathrm{O}_{2}-3=\mathrm{C}_{7} \mathrm{H}_{14}-3+\mathrm{HO}$ & $1.0044 E+39$ \\
R635 & $\mathrm{C}_{7} \mathrm{H}_{15} \mathrm{O}_{2}-2=\mathrm{C}_{7} \mathrm{H}_{14} \mathrm{OOH}-4$ & $2.5 E+10$ \\
R637 & $\mathrm{C}_{7} \mathrm{H}_{15} \mathrm{O}_{2}-4=\mathrm{C}_{7} \mathrm{H}_{14} \mathrm{OOH} 4-2$ & $5.0 E+10$ \\
R668 & $\mathrm{C}_{7} \mathrm{H}_{14} \mathrm{OOH}_{3}-5 \mathrm{O}_{2}=\mathrm{C}_{7} \mathrm{H}_{14} \mathrm{OOH}-5+\mathrm{O}_{2}$ & $1.389 E+23$ \\
R670 & $\mathrm{C}_{7} \mathrm{H}_{14} \mathrm{OOH} 1-3 \mathrm{O}_{2}=\mathrm{NC}_{7} \mathrm{KET} \mathrm{OH}_{13}+\mathrm{OH}$ & $2.5 E+10$ \\
\hline
\end{tabular}

For R78, compared with the ignition process of n-heptane air, the reaction is inhibited and the ignition delay time is prolonged. However, with the increase in $\mathrm{H}_{2}$, the influence of R78 is weakened and the influence of R3 is enhanced. Therefore, $\mathrm{H}_{2}$ has a stronger inhibitory effect on the ignition process.

Figures 10(b) and 10(c) show the sensitivity analysis of the important reactions for ignition of $n$ methane $/ \mathrm{H}_{2} / \mathrm{n}$ heptane mixtures in the high-temperature region. The results show that the sensitivity coefficient of R3 changes from positive to negative, from inhibition to promotion, which would produce more $\mathrm{H}$ radicals. In addition, reaction $\mathrm{R} 1$ also plays a leading role and the $\mathrm{H}$ radical produced by $\mathrm{R} 3$ will produce more $\mathrm{OH}$ radicals through the reaction $\mathrm{R}$.
When the $\mathrm{H}_{2}$ content increases, the sensitivity coefficients of the two reactions increase significantly. Therefore, the decrease in ignition delay caused by adding $\mathrm{H}_{2}$ in the hightemperature region is mainly attributed to R3 and R1.

The rates of production and consumption are an important basis for the chemical kinetic study of fuel oxidation. $\mathrm{OH}$ and $\mathrm{HO}_{2}$ are the most important free radicals to link the reaction path of methane $/ \mathrm{H}_{2} / \mathrm{n}$-heptane. The curves of ROP with temperature are shown in Figure 11. The dominant reactions related to the above free radicals are listed at the initial temperatures of $900 \mathrm{~K}, 1000 \mathrm{~K}$, and $1100 \mathrm{~K}$. It can be seen that with the increase in $\mathrm{H}_{2}$ content, the production and consumption rate of $\mathrm{OH}$ increase significantly, and the total reaction rate of $\mathrm{OH}$ increases-indicating that the addition of $\mathrm{H}_{2}$ promotes the corresponding reaction rate. Further increasing the concentration of $\mathrm{OH}$ in the free radical pool results in the increase in the total reactivity of the system. This can also explain that the addition of $\mathrm{H}_{2}$ in Figure 8 will increase the final temperature of the reaction system. However, the total reaction rate of $\mathrm{HO}_{2}$ has little effect with the addition of $\mathrm{H}_{2}$.

3.3. Effect of Syngas Addition. In this study, the volume ratios of $\mathrm{H}_{2}$ and $\mathrm{CO}$ in the syngas are $3: 1$ and $1: 1$. Figure 11 shows the ignition delay time changes in a methane/syngas/nheptane system with varying $\alpha$. As mentioned in the previous numerical setting section, changing $\beta$ will change the equivalence ratio of $n$-heptane, while changing $\alpha$ will change the mole fraction ratio of methane to syngas. Compared with the methane/ $\mathrm{H}_{2} / \mathrm{n}$-heptane blends previously observed, the effect of syngas addition on the ignition delay time of methane/syngas/n-heptane blends is similar. However, in the middle- and low-temperature regions, the ignition delay time decreases with the increase in CO content in syngas and 

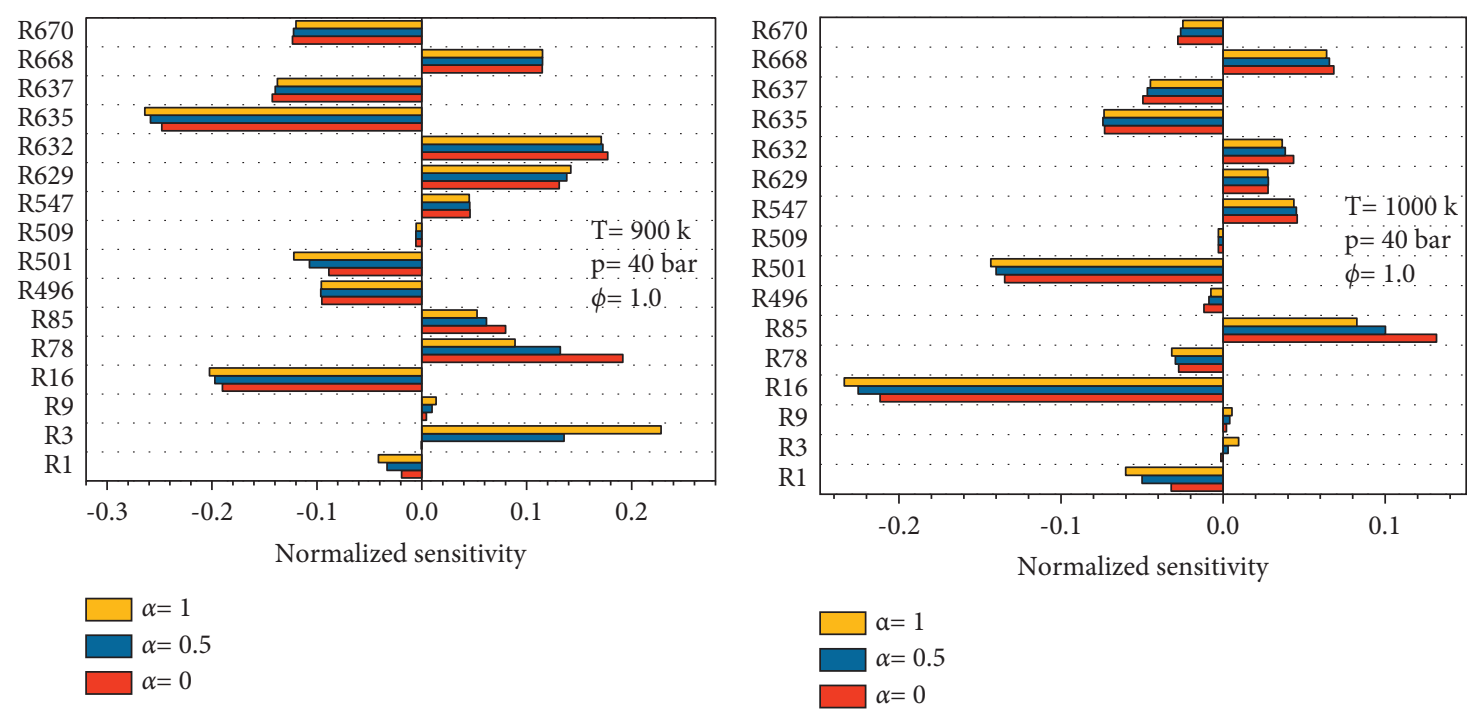

(a)

(b)

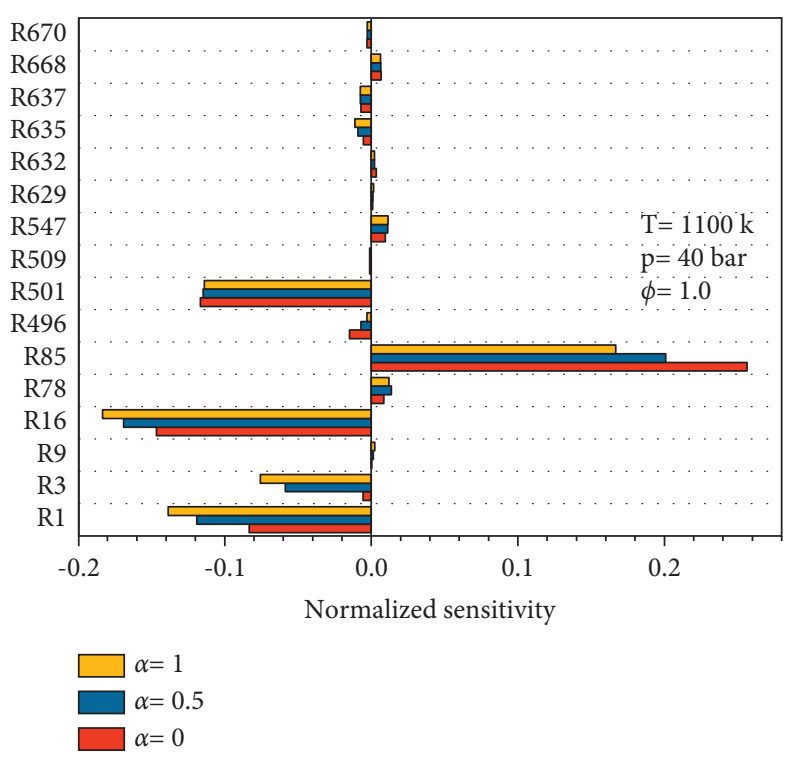

(c)

FigURE 10: Reaction sensitivity analysis of the ignition delay time for various $\alpha$ values in the different temperature ranges for methane/ $\mathrm{H}_{2} / \mathrm{n}$ heptane mixtures at $\beta=4.545 \times 10^{-2}, p=40 \mathrm{bar}$, and $\phi=1$.

the influence of the high-temperature regions is very small, which is the same as the conclusion of Aggarwal et al. [45]. In the same way, thermal and species evaluation, ROP, and sensitivity analysis were used to explain the phenomena in the simulation results.

Figure 12 shows the time evolution of reactants and some important species at $\beta=2.112 \times 10^{-2}$ and initial temperatures of $900 \mathrm{~K}$ and $1000 \mathrm{~K}$, respectively. Similar to the analysis in the previous section, Figure 12 shows that when the initial temperature is $900 \mathrm{~K}$, the ignition delay time increases with the increase in syngas fraction in the mixture. When the initial temperature is $1000 \mathrm{~K}$, the result is the opposite. When the initial temperature is $900 \mathrm{~K}$, the ignition process has the characteristics of two-stage ignition. The low-temperature reaction of n-heptane generates an $\mathrm{HO}_{2}$ radical. There are two peaks of the $\mathrm{HO}_{2}$ radical, which gradually decrease after the first peak and $\mathrm{HO}_{2}$ transforms into $\mathrm{H}_{2} \mathrm{O}_{2}$. This is the same result as the previous section's addition of hydrogen. Moreover, the increase in CO mole fraction is due to the decomposition of hydrocarbon to produce $\mathrm{CO}$, and the consumption reaction of $\mathrm{CO}$ mainly occurs near the ignition time. When the initial temperature is $1000 \mathrm{~K}$, the two-stage ignition characteristics disappear.

Figure 13 shows the effect of initial temperature and $\alpha$ on temperature evolution at $\beta=2.112 \times 10^{-2}, p=40 \mathrm{bar}$, and $\phi=0.5$. It can be seen that the addition of syngas will increase the final temperature of the mixed system of methane/nheptane. When the initial temperature is $900 \mathrm{~K}$, the initial temperature rise increases with the increase in $\mathrm{CO}$ content in syngas. However, when the initial temperature is $1000 \mathrm{~K}$, the 


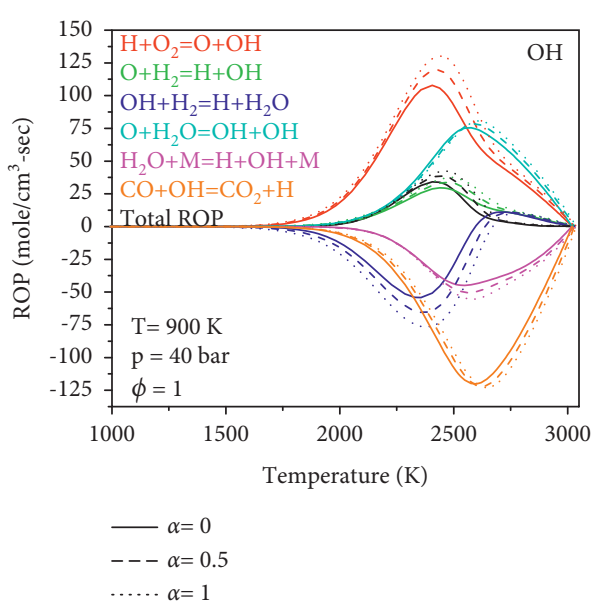

(a)

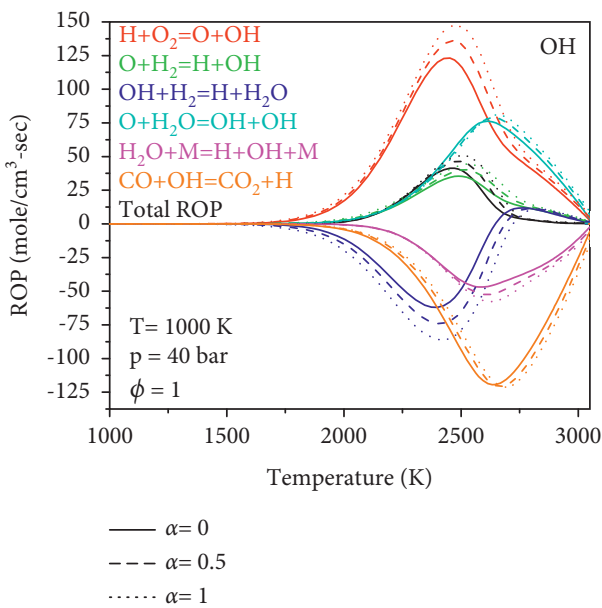

(c)

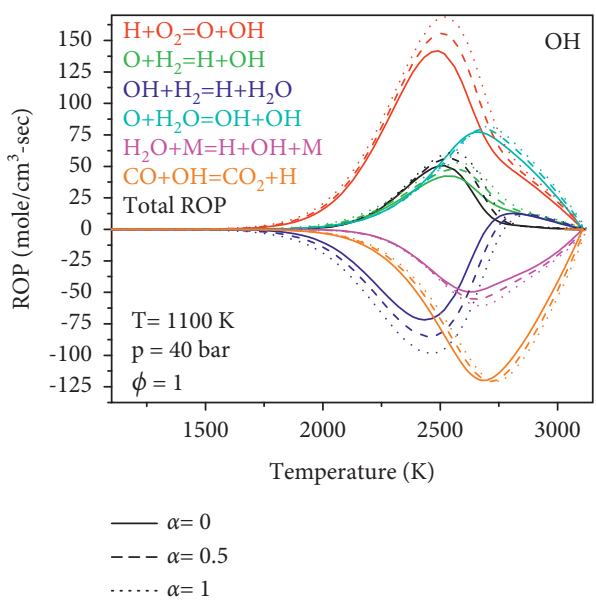

(e)

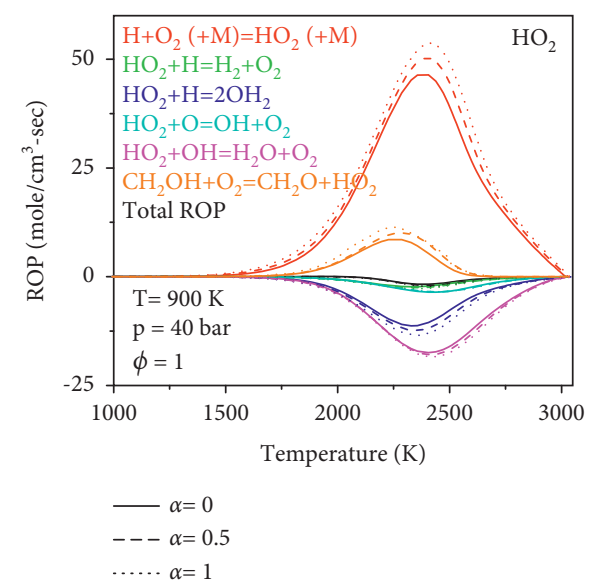

(b)

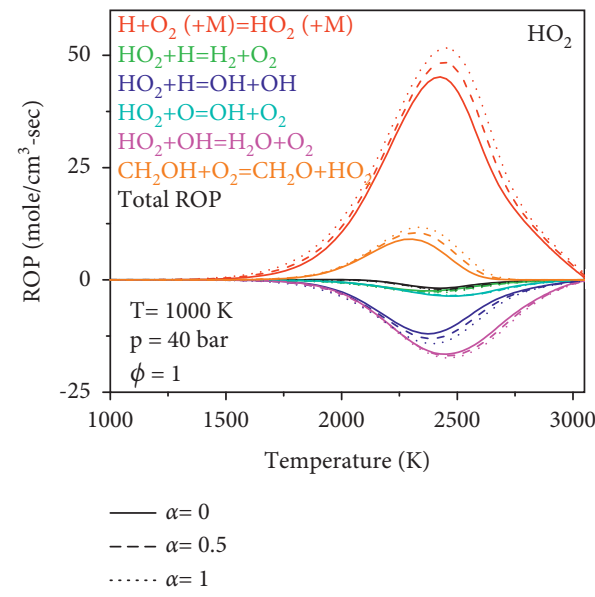

(d)

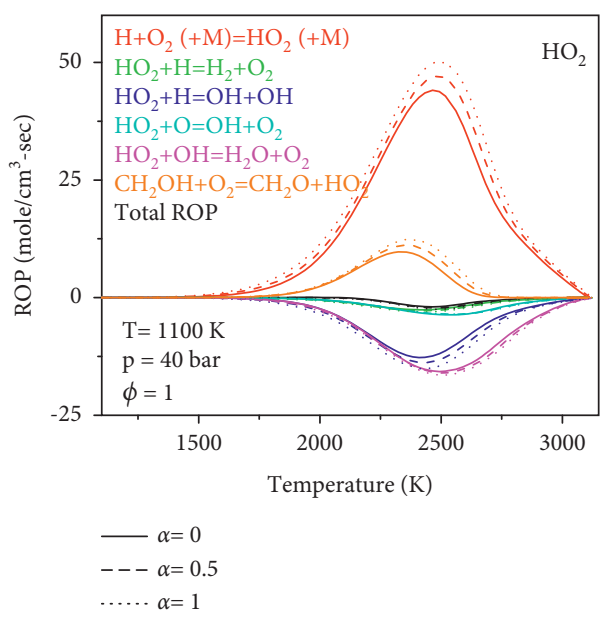

(f)

FIGURE 11: Rates of production and consumption of $\mathrm{OH}$ and $\mathrm{HO}_{2}$ for various $\alpha$ values in the different temperature ranges for methane/ $\mathrm{H}_{2} /$ n-heptane mixtures at $\beta=4.545 \times 10^{-2}, p=40 \mathrm{bar}$, and $\phi=1$.

initial temperature rise decreases due to the decrease in $\mathrm{H}_{2}$ content in the mixture. It can be explained that in Figure 14, the ignition delay time of methane/syngas/n-heptane mixture system at the medium- and low-temperature regions decreases obviously when CO is added, but it has little effect at the high-temperature regions.

Figure 15 shows the ratio of the second-stage ignition delay time at the different initial temperatures. The effect of 


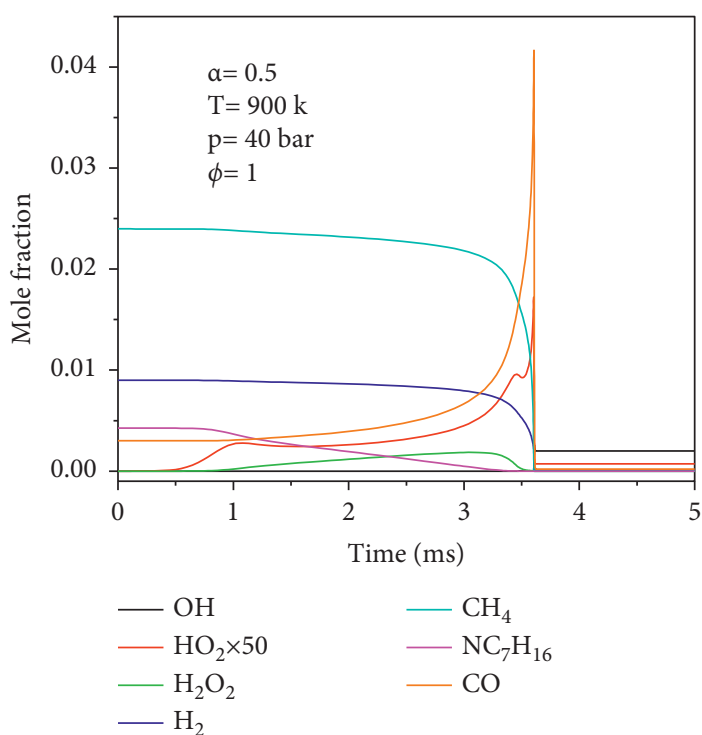

(a)

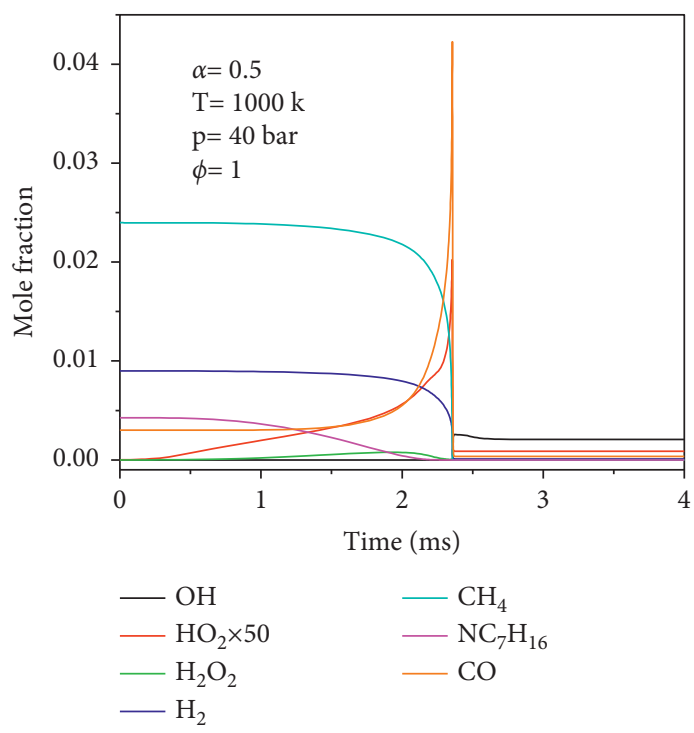

(c)

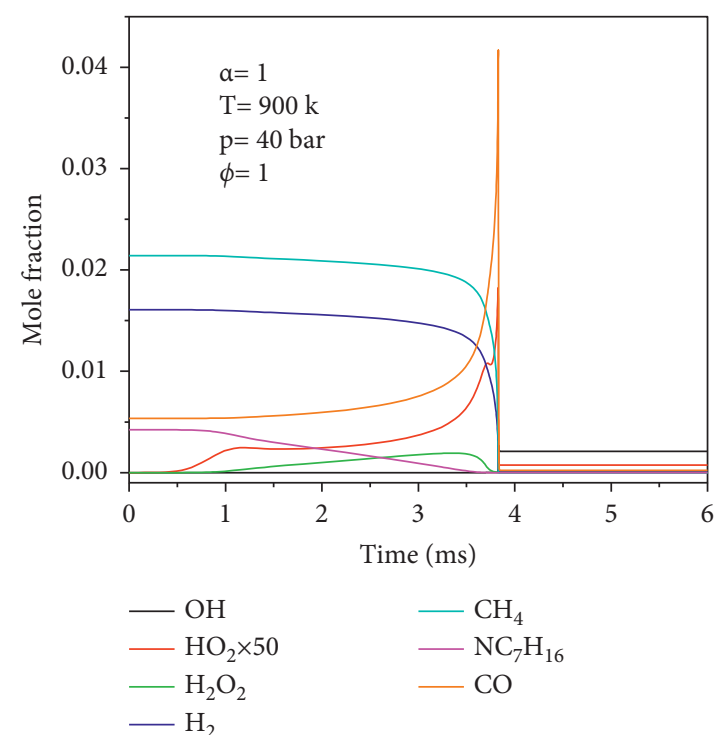

(b)

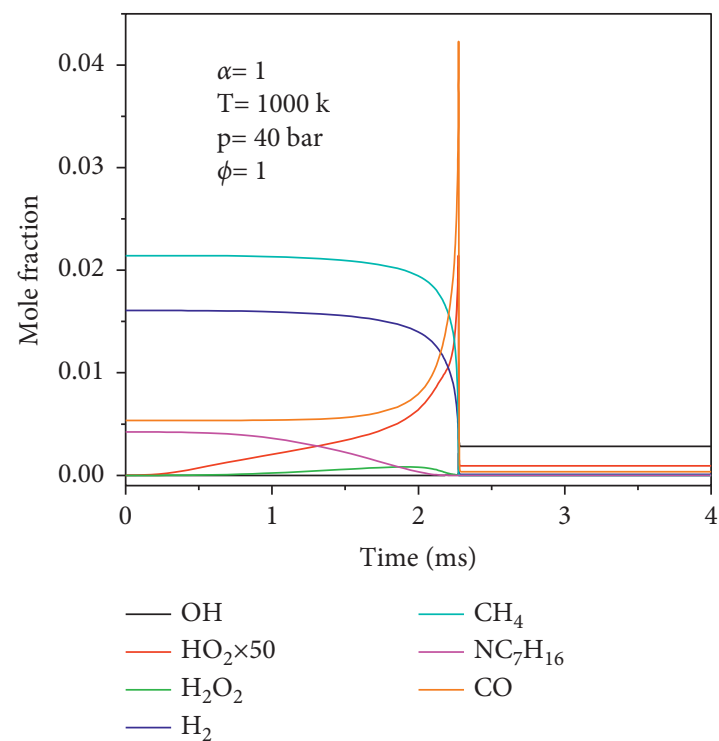

(d)

Figure 12: Effect of initial temperature and $\alpha$ on species evolution for methane $/ \mathrm{H}_{2} / n$-heptane mixtures at $\beta=2.112 \times 10^{-2}$, bar, and $\phi=1$.

syngas addition on ignition delay is similar to that of $\mathrm{H}_{2}$ addition in the previous part. However, with the increase in $\mathrm{CO}$ content in syngas, the effect on ignition delay in the second stage is weakened, and it is obvious in the lowtemperature region. These aspects will be further studied in the next sensitivity analysis.

Based on the sensitivity analysis of the key reactions in the previous part, two important reactions about the $\mathrm{CO}$ oxidation process are added as shown in Table 2. Figure 16 shows the sensitivity analysis of the important reactions for ignition of methane/syngas/n-heptane mixtures. Figure 14 shows that increasing CO content in syngas will lead to a decrease in ignition delay. Compared with the same proportion of $\mathrm{H}_{2}$ added in Figure 10, it can be seen that the influence of $\mathrm{H}_{2}$ on the mixture system is greater than that of $\mathrm{CO}$, which can also be said that the addition of $\mathrm{CO}$ has little influence on the chemical properties of the ignition process. This is because the activation energy of $\mathrm{CO}+\mathrm{O}_{2}=\mathrm{CO}_{2}+\mathrm{O}$ is relatively large and fewer $\mathrm{O}$ atoms are generated, which will not accelerate the reaction process [24]. The oxidation of $\mathrm{CO}$ requires a small amount of $\mathrm{OH}$ radicals $\left(\mathrm{CO}+\mathrm{OH}=\mathrm{CO}_{2}+\mathrm{H}\right)$, and the $\mathrm{H}$ atom promotes the chain branching reaction, which is the main reason why $\mathrm{CO}$ can reduce the ignition delay time. However, the addition of $\mathrm{CO}$ will reduce the importance of $\mathrm{R} 3$ in the reaction process-resulting in the weakening of the effect of $\mathrm{H}_{2}$ on ignition delay. 


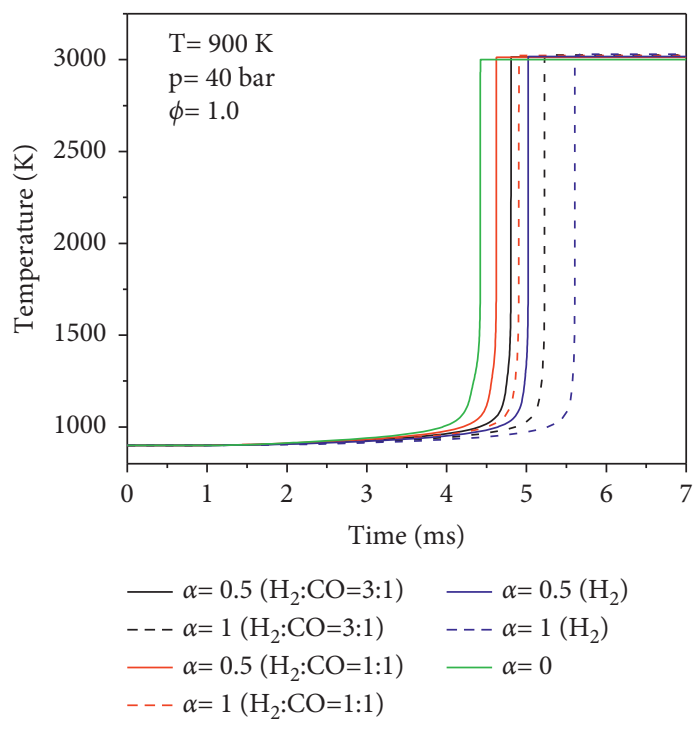

(a)

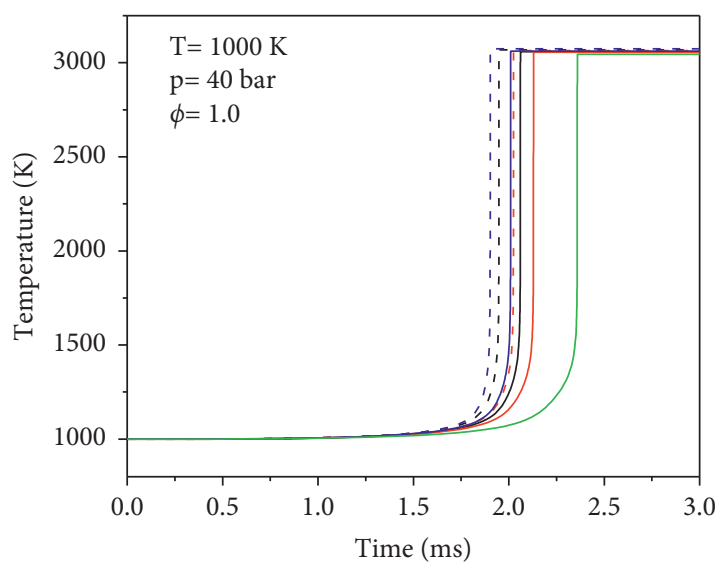

$$
\begin{aligned}
-\alpha=0.5\left(\mathrm{H}_{2}: \mathrm{CO}=3: 1\right) & -\alpha=0.5\left(\mathrm{H}_{2}\right) \\
--\alpha=1\left(\mathrm{H}_{2}: \mathrm{CO}=3: 1\right) & --\alpha=1\left(\mathrm{H}_{2}\right) \\
-\alpha=0.5\left(\mathrm{H}_{2}: \mathrm{CO}=1: 1\right) & -\alpha=0 \\
--\alpha=1\left(\mathrm{H}_{2}: \mathrm{CO}=1: 1\right) &
\end{aligned}
$$

(b)

FIgURE 13: Effect of initial temperature and $\alpha$ on temperature evolution at $\beta=2.112 \times 10^{-2}$, bar, and $\phi=1$.

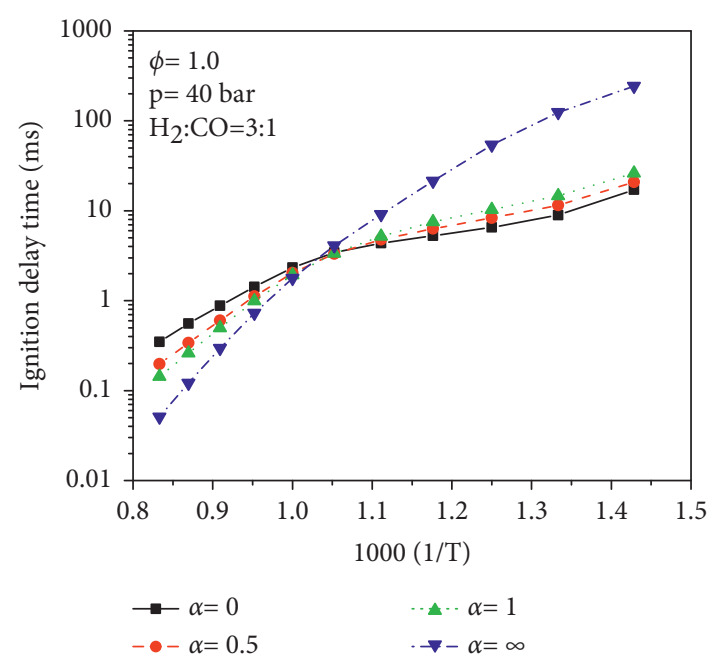

(a)

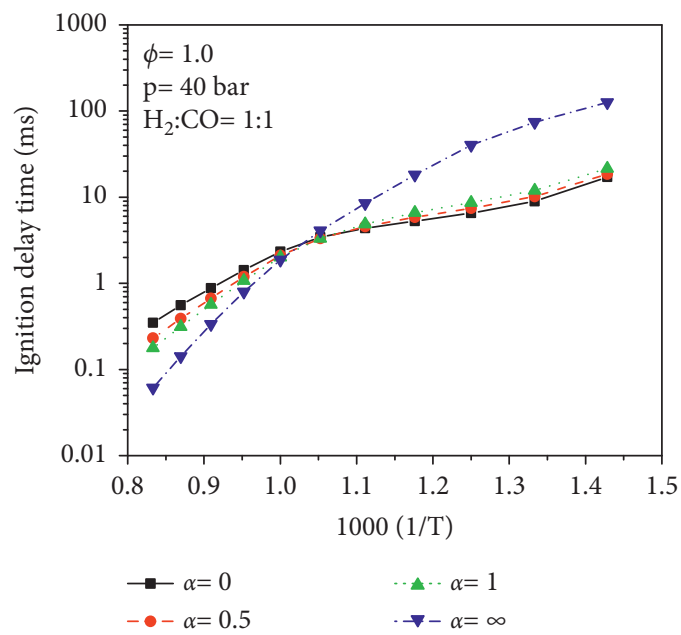

(c)

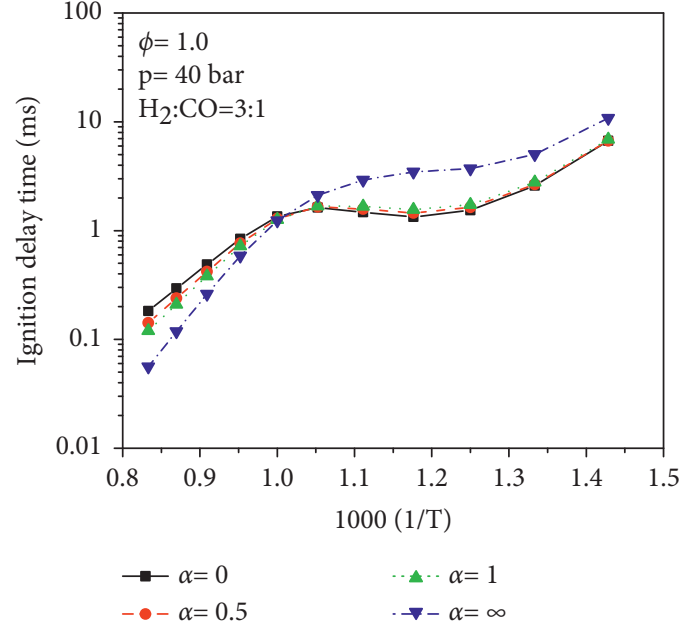

(b)

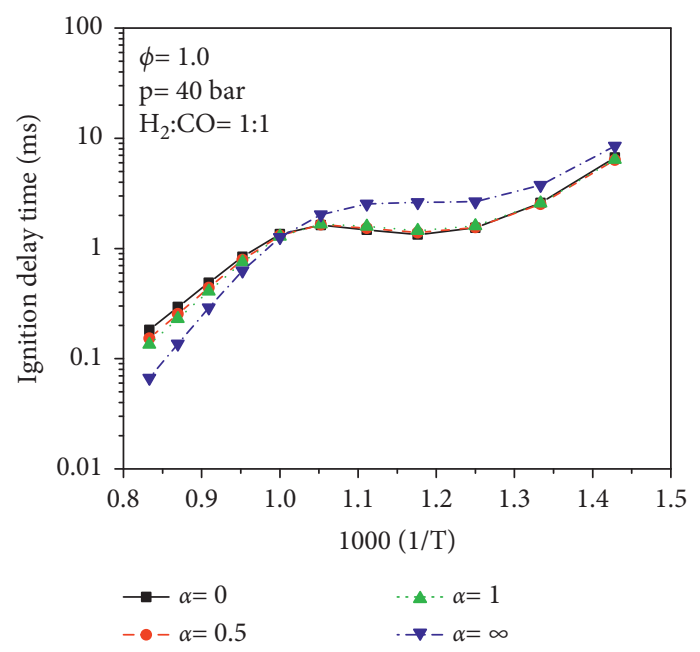

(d)

Figure 14: Ignition delay time of different $\alpha$ values for methane/syngas/n-heptane mixtures, (a) and (c) $\beta=2.112 \times 10^{-2}$, (b) and (d) $\beta=4.545 \times 10^{-2}$. 


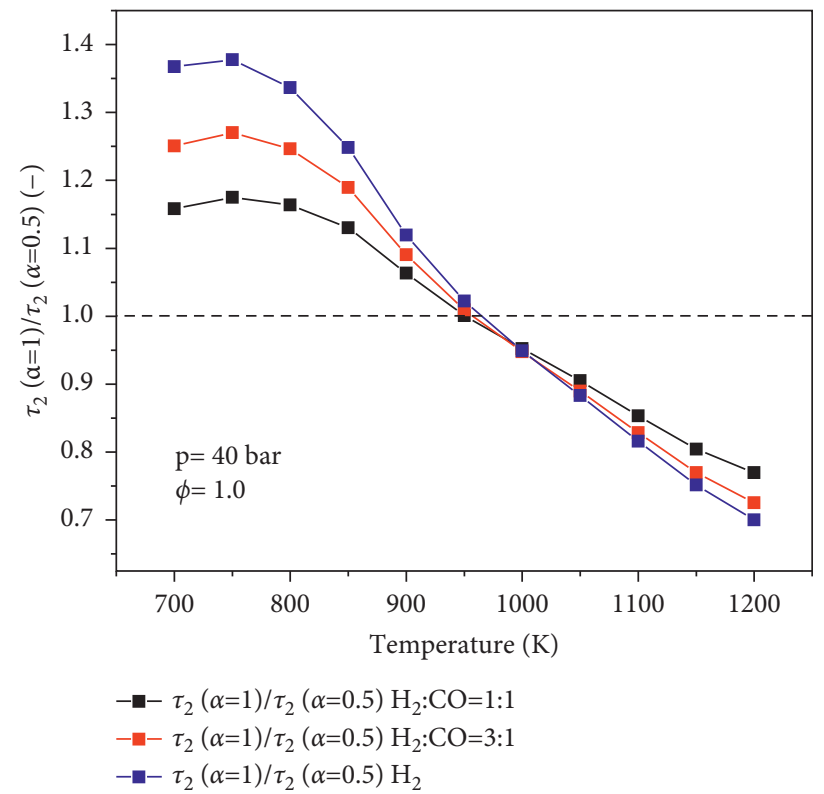

Figure 15: Ratio of the second-stage ignition delay time of different initial temperatures for methane/syngas/n-heptane mixtures at $\beta=2.112 \times 10^{-2}, p=40$ bar, and $\phi=1$.

TABLE 2: Important reactions for the ignition processes of CO.

\begin{tabular}{lcr}
\hline Number & Elementary reactions & A \\
\hline R23 & $\mathrm{CO}+\mathrm{O}_{2}=\mathrm{CO}_{2}+\mathrm{O}$ & $1.05 E+12$ \\
R24 & $\mathrm{CO}+\mathrm{OH}=\mathrm{CO}_{2}+\mathrm{H}$ & $1.784 E+5$ \\
\hline
\end{tabular}
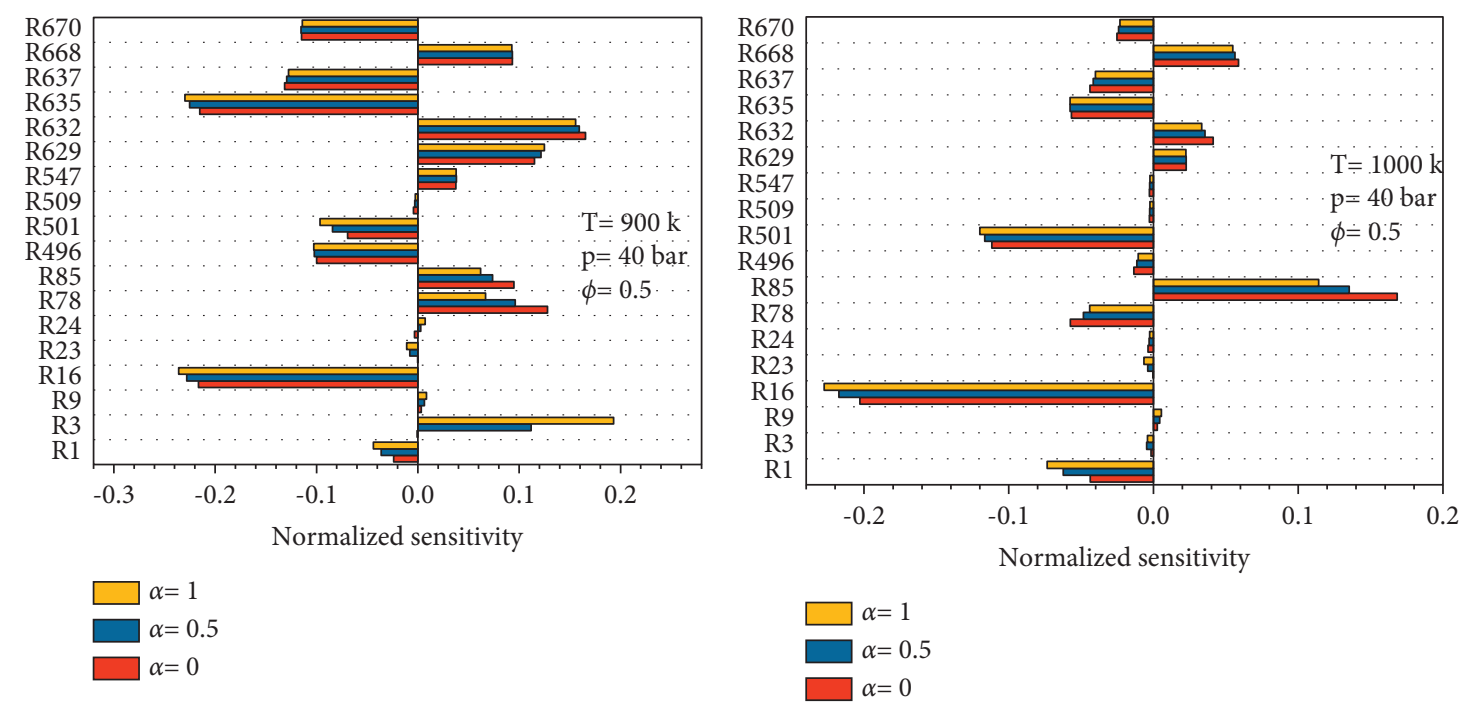

(a)

(b)

Figure 16: Continued. 


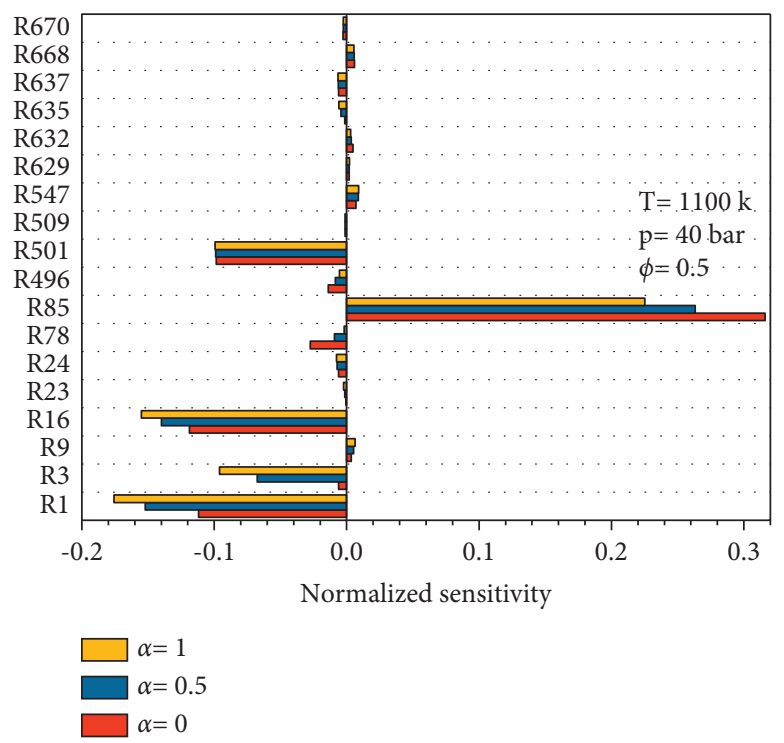

(c)

Figure 16: Reaction sensitivity analysis of the ignition delay time for various $\alpha$ values in the different temperature ranges for methane/ syngas/n-heptane mixtures at $\beta=2.112 \times 10^{-2}, p=40 \mathrm{bar}$, and $\phi=0.5$.

\section{Conclusion}

In this study, the effects of $\mathrm{H}_{2}$ and syngas on the ignition characteristics of the methane/n-heptane mixture under different conditions were investigated numerically. Combined with sensitivity analysis and the ROP analysis, the effect of $\mathrm{H}_{2}$ and syngas addition on the whole reaction process was revealed. The main conclusions are as follows:

(1) The results showed that the decomposition rate of n-heptane was faster than that of methane, the addition of methane could obviously inhibit the ignition delay time of dual fuel, and the addition of methane could delay the decomposition of n-heptane. Therefore, the ignition delay time of n-heptane was prolonged by the addition of methane.

(2) The ignition delay time of the methane/n-heptane mixture was prolonged after $\mathrm{H}_{2}$ addition in the middle- and low-temperature ranges. This was due to the fact that R3 was an endothermic reaction, which consumed $\mathrm{OH}$ radicals, inhibited the reaction process, and reduced the rise of temperature and free radical concentration in the initial stage. In the hightemperature range, adding $\mathrm{H}_{2}$ shortened the ignition delay time of the mixture system. This was due to the significant increase in sensitivity coefficients of R1 and $\mathrm{R} 3$ and the generation of $\mathrm{OH}$ radicals, which promoted the reaction process. Therefore, the reduction in ignition delay caused by $\mathrm{H}_{2}$ addition in high-temperature region was mainly attributed to R3 and $\mathrm{R} 1$.

(3) At different initial temperatures of methane/syngas/ n-heptane mixture, the ignition delay time of methane/syngas/n-heptane mixture decreased with the addition of $\mathrm{CO}$ in the medium- and low- temperature regions, and the influence of the hightemperature region was very small. Besides, the consumption of $\mathrm{CO}$ mainly occurred near the ignition time.

(4) The addition of $\mathrm{H}_{2}$ and syngas slightly increased the final temperature of the methane/n-heptane mixture system, which has a reference value for the practical dual-fuel engine, especially for the emission problem.

Through chemical kinetic analysis, the main reaction that affects the ignition process of methane/n-heptane/reformed gas mixture is further studied. This research can expand the theoretical basis of the influence of reformed gas on ignition delay. Studies have shown that adding reformed gas to dual-fuel engines needs to consider the influence of $\mathrm{H}_{2}$ and $\mathrm{CO}$ contents. The chemical effect of hydrogen has a great impact on dual-fuel engines. This provides guidance for the control of the combustion phase of dual-fuel engines, especially in the study of the influence of different natural gas equivalent ratios on dual-fuel engines.

\section{Data Availability}

All data, models, and code generated or used during the study appear in the submitted article.

\section{Conflicts of Interest}

The author declares that there are no conflicts of interest regarding the publication of this study.

\section{Acknowledgments}

This work was supported by the National Natural Science Foundation of China. Grant number is 11272213. 


\section{References}

[1] T. Korakianitis, A. M. Namasivayam, and R. J. Crookes, "Natural-gas fueled spark-ignition (SI) and compression-ignition (CI) engine performance and emissions," Progress in Energy and Combustion Science, vol. 37, no. 1, pp. 89-112, 2011.

[2] M. S. Lounici, K. Loubar, L. Tarabet, M. Balistrou, D.-C. Niculescu, and M. Tazerout, "Towards improvement of natural gas-diesel dual fuel mode: an experimental investigation on performance and exhaust emissions," Energy, vol. 64, pp. 200-211, 2014.

[3] L. Wei and P. Geng, "A review on natural gas/diesel dual fuel combustion, emissions and performance," Fuel Processing Technology, vol. 142, pp. 264-278, 2016.

[4] M. M. Abdelaal and A. H. Hegab, "Combustion and emission characteristics of a natural gas-fueled diesel engine with EGR," Energy Conversion and Management, vol. 64, pp. 301-312, 2012.

[5] J. Zheng, J. Wang, Z. Zhao, D. Wang, and Z. Huang, "Effect of equivalence ratio on combustion and emissions of a dual-fuel natural gas engine ignited with diesel," Applied Thermal Engineering, vol. 146, pp. 738-751, 2019.

[6] N. Ryan Walker, M. L. Wissink, D. A. DelVescovo, and R. D. Reitz, "Natural gas for high load dual-fuel reactivity controlled compression ignition in heavy-duty engines," Journal of Energy Resources Technology, vol. 137, no. 4, Article ID 042202, 2015.

[7] R. D. Reitz and G. Duraisamy, "Review of high efficiency and clean reactivity controlled compression ignition (RCCI) combustion in internal combustion engines," Progress in Energy and Combustion Science, vol. 46, pp. 12-71, 2015.

[8] P. Rahnama, A. Paykani, and R. D. Reitz, "A numerical study of the effects of using hydrogen, reformer gas and nitrogen on combustion, emissions and load limits of a heavy duty natural gas/diesel RCCI engine," Applied Energy, vol. 193, pp. 182$198,2017$.

[9] D. E. Nieman, A. B. Dempsey, and R. D. Reitz, "Heavy-Duty RCCI operation using natural gas and diesel," SAE International Journal of Engines, vol. 5, no. 2, pp. 270-285, 2012.

[10] L. Zhu, B. Li, A. Li et al., "Effects of fuel reforming on largebore low-speed two-stroke dual fuel marine engine combined with EGR and injection strategy," International Journal of Hydrogen Energy, vol. 45, no. 53, pp. 29505-29517, 2020.

[11] S. Karimkashi, H. Kahila, O. Kaario, M. Larmi, and V. Vuorinen, "Numerical study on tri-fuel combustion: ignition properties of hydrogen-enriched methane-diesel and methanol-diesel mixtures," International Journal of Hydrogen Energy, vol. 45, no. 7, pp. 4946-4962, 2020.

[12] S. Cordiner, M. Gambino, S. Iannaccone, V. Rocco, and R. Scarcelli, "Numerical and experimental analysis of combustion and exhaust emissions in a dual-fuel diesel/natural gas engine," Energy \& Fuels, vol. 22, no. 3, pp. 193-197, 2008.

[13] X. Wang, X. Wang, and $\mathrm{H}$. Yu, "The functions of Pt located at different positions of HZSM-5 in $\mathrm{H}_{2}$-SCR," Chemical Engineering Journal, vol. 355, 2018.

[14] S. Yoon, J. Collins, A. Thiruvengadam, M. Gautam, J. Herner, and A. Ayala, "Criteria pollutant and greenhouse gas emissions from $\mathrm{CNG}$ transit buses equipped with three-way catalysts compared to lean-burn engines and oxidation catalyst technologies," Journal of the Air \& Waste Management Association, vol. 63, no. 8, pp. 926-933, 2013.

[15] Z.-Y. Sun, F.-S. Liu, X.-H. Liu, B.-G. Sun, and D.-W. Sun, "Research and development of hydrogen fuelled engines in
China," International Journal of Hydrogen Energy, vol. 37, no. 1, pp. 664-681, 2012.

[16] E. Kahraman, S. Cihangir Ozcanll, and B. Ozerdem, "An experimental study on performance and emission characteristics of a hydrogen fuelled spark ignition engine," International Journal of Hydrogen Energy, vol. 32, no. 12, pp. 2066-2072, 2007.

[17] Z. He, Z. Gao, L. Zhu et al., "Effects of H2 and CO enrichment on the combustion, emission and performance characteristics of spark ignition natural gas engine," Fuel, vol. 183, pp. 230-237, 2016.

[18] T. Blumberg, Y. D. Lee, T. Morosuk, and G. Tsatsaronis, "Exergoenvironmental analysis of methanol production by steam reforming and autothermal reforming of natural gas," Energy, vol. 181, 2019.

[19] F. D. F. Chuahy and S. L. Kokjohn, "High efficiency dual-fuel combustion through thermochemical recovery and diesel reforming," Applied Energy, vol. 195, pp. 503-522, 2017.

[20] E. D. Sail, D. A. Morgenstern, J. P. Fornango, J. W. Taylor, N. Chomic, and J. Wheeler, "Reforming of ethanol with exhaust heat at automotive scale," Energy \& Fuels, vol. 27, pp. 5579-5588, 2013.

[21] H. Guo and W. S. Neill, "The effect of hydrogen addition on combustion and emission characteristics of an n-heptane fuelled HCCI engine," International Journal of Hydrogen Energy, vol. 38, no. 26, pp. 11429-11437, 2013.

[22] C. Geng, H. Liu, X. Ran, and M. Yao, "The impact of low temperature reforming (LTR) products of fuel-rich n-heptane on compression ignition engine combustion," Fuel, vol. 229, 2018.

[23] L. Zhu, Z. He, Z. Xu et al., "In-cylinder thermochemical fuel reforming (TFR) in a spark-ignition natural gas engine," Proceedings of the Combustion Institute, vol. 36, no. 3, pp. 3487-3497, 2016.

[24] P. Rahnama, A. Paykani, V. Bordbar, and R. D. Reitz, "A numerical study of the effects of reformer gas composition on the combustion and emission characteristics of a natural gas/ diesel RCCI engine enriched with reformer gas," Fuel, vol. 209, no. dec.1, pp. 742-753, 2017.

[25] J. Li, X. Liu, H. Liu et al., "Kinetic study of the ignition process of methane/n-heptane fuel blends under high-pressure directinjection natural gas engine conditions," Energy \& Fuels, vol. 34, no. 11, pp. 14796-14813, 2020.

[26] M. Ghaderi Masouleh, A. Wehrfritz, O. Kaario, H. Kahila, and V. Vuorinen, "Comparative study on chemical kinetic schemes for dual-fuel combustion of n-dodecane/methane blends," Fuel, vol. 191, pp. 62-76, 2017.

[27] J. Li, H. Liu, X. Liu et al., "Development of a simplified n-heptane/methane model for high-pressure direct-injection natural gas marine engines," Frontiers in Energy, vol. 15, no. 2, pp. 405-420, 2021.

[28] J. Li, H. Liu, X. Liu, Y. Ye, H. Wang, and M. Yao, "Investigation of the combustion kinetics process in a high-pressure direct injection natural gas marine engine," Energy \& Fuels, vol. 35, no. 8, pp. 6785-6797, 2021.

[29] J. C. Ong, J. H. Walther, S. Xu, S. Zhong, X.-S. Bai, and K. M. Pang, "Effects of ambient pressure and nozzle diameter on ignition characteristics in diesel spray combustion," Fuel, vol. 290, no. 1-2, Article ID 119887, 2021.

[30] K. Zhang, Z. Liang, J. Wang, and Z. Wang, "Diesel diffusion flame simulation using reduced $n$-heptane oxidation mechanism," Applied Energy, vol. 105, no. may, pp. 223-228, 2013.

[31] X. Zhang, C. Yuan, L. Zhou, W. Zhao, Z. Liu, and H. Wei, "Effects of initial temperature on ignition and flame 
propagation of dual-fuel mixture in mixing layer," Combustion and Flame, vol. 225, pp. 468-484, 2021.

[32] A. Hockett, G. Hampson, and A. J. Marchese, "Development and validation of a reduced chemical kinetic mechanism for computational fluid dynamics simulations of natural gas/ diesel dual-fuel engines," Energy \& Fuels, vol. 30, no. 3, pp. 2414-2427, 2016.

[33] ANSYS CHEMKIN 17.0. ANSYS Reaction Design, San Diego, 2016.

[34] Y. Ra and R. D. Reitz, "A reduced chemical kinetic model for IC engine combustion simulations with primary reference fuels," Combustion and Flame, vol. 155, no. 4, pp. 713-738, 2008.

[35] U. Burke, K. P. Somers, P. O’Toole et al., "An ignition delay and kinetic modeling study of methane, dimethyl ether, and their mixtures at high pressures," Combustion and Flame, vol. 162, no. 2, pp. 315-330, 2015.

[36] J. Liang, Z. Zhang, G. Li, Q. Wan, L. Xu, and S. Fan, "Experimental and kinetic studies of ignition processes of the methane-n-heptane mixtures," Fuel, vol. 235, pp. 522-529, 2019.

[37] Y. Zhang, "Experimental and modeling study on auto-ignition of methane/hydrogen blends at elevated pressures," SAE Technical Paper Series, vol. 1, 2014.

[38] E. L. Petersen, J. M. Hall, S. D. Smith, J. De Vries, A. Amadio, and M. W. Crofton, "Ignition of lean methane-based fuel blends at gas turbine pressures," Turbo Expo 2005, ASMEDC, vol. 2, pp. 367-379, , Reno, Nevada, USA, 2005.

[39] A. Kéromnès, W. K. Metcalfe, K. A. Heufer et al., "An experimental and detailed chemical kinetic modeling study of hydrogen and syngas mixture oxidation at elevated pressures," Combustion and Flame, vol. 160, no. 6, pp. 995-1011, 2013.

[40] D. Healy, D. M. Kalitan, C. J. Aul, E. L. Petersen, G. Bourque, and H. J. Curran, "Oxidation of C1-C5 alkane quinternary natural gas mixtures at high pressures," Energy \& Fuels, vol. 24, no. 3, pp. 1521-1528, 2010.

[41] H. Curran, P. Gaffuri, W. J. Pitz, and C. K. Westbrook, "A comprehensive modeling study of iso-octane oxidation," Combustion and Flame, vol. 129, no. 3, pp. 253-280, 2002.

[42] F. Xiao and S. K. Aggarwal, "Two-stage ignition and NTC phenomenon in diesel engines," Fuel, vol. 144, pp. 188-196, 2015.

[43] H. Wei, J. Qi, L. Zhou, W. Zhao, and G. Shu, "Ignition characteristics of methane/n-heptane fuel blends under engine-like conditions," Energy \& Fuels, vol. 32, no. 5, pp. 6264-6277, 2018.

[44] Z. Gong, L. Feng, L. Wei, W. Qu, and L. Li, "Shock tube and kinetic study on ignition characteristics of lean methane/nheptane mixtures at low and elevated pressures," Energy, vol. 197, p. 117242, 2020.

[45] S. Aggarwal, T. Helma, and D. Li, "A numerical investigation on the ignition of JP-8 surrogates blended with hydrogen and syngas," International Journal of Advances in Engineering Sciences \& Applied Mathematics, vol. 6, no. 1-2, pp. 49-64, 2014. 